\title{
$\mathrm{BMJ}$
}

\section{Value of symptoms and additional diagnostic tests for colorectal cancer in primary care: systematic review and meta-analysis}

${ }^{1}$ Department of General Practice, EMGO Institute for Health and Care Research, VU University Medical Center, Van der Boechorststraat 7 , 1081 BT Amsterdam, Netherlands

${ }^{2}$ Arthritis Research UK National Primary Care Centre, Keele University, Keele, Staffordshire ST5 5BG

${ }^{3}$ Department of Public and Occupational Health, EMGO Institute for Health and Care Research, VU University Medical Center, Amsterdam

${ }^{4}$ Department of Gastroenterology and Hepatology, VU University Medical Center, Amsterdam

${ }^{5}$ Department of Epidemiology and Biostatistics, EMGO Institute for Health and Care Research, VU University Medical Center,

Amsterdam

Correspondence to: $\mathrm{HC} \mathrm{W}$ de Vet hcw.devet@vumc.nl

Cite this as: BMJ 2010;340:c1269 doi:10.1136/bmj.c1269

\author{
Petra Jellema, research fellow, ${ }^{1}$ Daniëlle A W M van der Windt, professor in primary care epidemiology, ${ }^{1,2}$ \\ David J Bruinvels, senior researcher, ${ }^{3}$ Christian D Mallen, senior lecturer in general practice, ${ }^{2}$ Stijn J B van \\ Weyenberg, affiliated professor of gastroenterology, ${ }^{4}$ Chris ) Mulder, professor of gastroenterology, ${ }^{4}$ Henrica \\ CW de Vet, professor of clinimetrics ${ }^{5}$
}

\section{ABSTRACT}

Objective To summarise available evidence on diagnostic tests that might help primary care physicians to identify patients with an increased risk for colorectal cancer among those consulting for non-acute lower abdominal symptoms.

Data sources PubMed, Embase, and reference screening. Study eligibility criteria Studies were selected if the design was a diagnostic study; the patients were adults consulting because of non-acute lower abdominal symptoms; tests included signs, symptoms, blood tests, or faecal tests.

Study appraisal and synthesis methods Two reviewers independently assessed quality with a modified version of the QUADAS tool and extracted data. We present diagnostic two by two tables and pooled estimates of sensitivity and specificity. We refrained from pooling when there was considerable clinical or statistical heterogeneity.

Results 47 primary diagnostic studies were included. Sensitivity was consistently high for age $\geq 50$ (range 0.81 . 0.96 , median 0.91$)$, a referral guideline $(0.80-0.94,0.92)$, and immunochemical faeces tests $(0.70-1.00,0.95)$. Of these, only specificity of the faeces tests was good. Specificity was consistently high for family history $(0.75$ $0.98,0.91)$, weight loss $(0.72-0.96,0.89)$, and iron deficiency anaemia $(0.83-0.95,0.92)$, but all tests lacked sensitivity. None of these six tests was (sufficiently) studied in primary care.

Conclusions Although combinations of symptom and results of immunochemical faeces tests showed good diagnostic performance for colorectal cancer, evidence from primary care is lacking. High quality studies on their role in the diagnostic investigation of colorectal cancer in primary care are urgently needed.

\section{INTRODUCTION}

Colorectal cancer is the second most common cancer in Europe. ${ }^{12}$ The five year survival rate for early stage colorectal cancer is greater than $90 \%$, whereas the five year survival rate for those diagnosed with widespread cancer is less than $10 \%{ }^{23}$ Early diagnosis is therefore of utmost importance. As patients with abdominal symptoms usually present to primary care, ${ }^{4}$ it is important that general practitioners can identify those at increased risk. This is not straightforward as abdominal symptoms are common in general practice, ${ }^{5}$ but each year a general practitioner would probably encounter no more than one new patient with colorectal cancer. ${ }^{6}$

Diagnostic tests could help general practitioners in the diagnostic process. To be of value in primary care, diagnostic tests should be directly accessible to general practitioners and their diagnostic accuracy should have been demonstrated in this setting. These include the signs and symptoms found with medical history and physical examination, blood tests, and faecal occult blood tests. Several guidelines have been developed to assist general practitioners in the diagnostic process. For example, in 2000 the Department of Health of England and Wales introduced guidelines so that all patients with suspected colorectal cancer could be seen by a specialist within two weeks of referral (TWR guideline, see appendix A on bmj.com). ${ }^{7}$ This referral guideline, however, has been criticised for using symptoms that are so common among the general practice population (such as change in bowel habits) that many referrals can falsely be classified as high risk. ${ }^{8}$ Although the evidence for ${ }^{6}$ and compliance with ${ }^{9}$ this guideline has already been reviewed, as has its effect on colorectal services, ${ }^{10}$ a meta-analysis of the diagnostic performance of the guideline itself is lacking. Other researchers advocate faecal blood testing in patients with symptoms as a guide to the urgency of investigation. ${ }^{112}$ Guaiac based tests are inexpensive but sensitive to diet and medication, and immunochemical based tests react only to human haemoglobin ${ }^{13}$ but are more expensive ( $\$ 15(€ 11) v \$ 22(€ 16)$, respectively $\left.{ }^{14}\right)$. In our hospital costs are around $€ 11.80$ (£10.60) and $€ 18.00$ (£16.20), respectively.

The challenge in primary care is to find a sensitive test that does not result in too many false positives. ${ }^{15}$ We summarised all the available evidence on the 
Table 1| Results of risk of bias assessment per study according to items on checklist for the quality assessment of diagnostic accuracy studies ${ }^{20 \star}$

\begin{tabular}{|c|c|c|c|c|c|c|c|c|c|c|c|}
\hline & 1 & 2 & 3 & 4 & 5 & 6 & 7 & 8 & 9 & 10 & 11 \\
\hline Bafandeh 2008† & + & + & + & + & + & + & + & $?$ & $?$ & + & + \\
\hline Barwick 2004 & $?$ & + & $?$ & + & - & - & - & - & + & + & ? \\
\hline Bjerregaard 2007 & + & + & + & + & $?$ & - & - & - & ? & + & + \\
\hline Bellentani 1990 & + & + & + & + & - & + & - & ? & ? & + & ? \\
\hline Brewster 1994 & $?$ & + & + & + & - & + & + & ? & ? & + & - \\
\hline Castiglione 1987 & + & + & + & + & - & - & - & $?$ & $?$ & - & + \\
\hline Charalambopoulos 2000 & $?$ & $?$ & + & ? & + & + & + & ? & + & + & + \\
\hline Chohan 2005 & $?$ & $?$ & $?$ & $?$ & $?$ & $?$ & $?$ & - & + & + & + \\
\hline Debnath 2002 & $?$ & + & $?$ & + & $?$ & ? & ? & - & + & + & ? \\
\hline Eccersley 2003 & $?$ & + & + & - & - & + & - & ? & + & + & + \\
\hline Ellis 2005 & + & $?$ & + & + & + & - & - & $?$ & $?$ & - & + \\
\hline Falkson 1993 & $?$ & + & $?$ & + & + & - & - & $?$ & $?$ & + & + \\
\hline Farrands 1985 & $?$ & ? & + & ? & - & + & - & ? & ? & + & + \\
\hline Flashman 2004 & $?$ & + & $?$ & + & $?$ & $?$ & $?$ & - & $?$ & + & + \\
\hline Fijten 1995 & + & $?$ & $?$ & + & + & - & - & $?$ & $?$ & + & $?$ \\
\hline Goulston 1980 & $?$ & + & + & ? & - & $?$ & - & ? & ? & + & ? \\
\hline Jeanson 1994 & $?$ & $?$ & $?$ & $?$ & $?$ & + & + & $?$ & $?$ & + & + \\
\hline Kimmig 1989 & $?$ & + & + & $?$ & + & + & + & $?$ & $?$ & + & $?$ \\
\hline Leicester 1983 & $?$ & $?$ & + & $?$ & - & - & - & $?$ & $?$ & + & + \\
\hline Levi 2007 & $?$ & $?$ & + & $?$ & + & + & + & + & + & $?$ & $?$ \\
\hline Mahon 2002 & $?$ & + & + & $?$ & - & - & - & $?$ & $?$ & + & + \\
\hline Mant 1989 & + & + & + & + & - & + & - & $?$ & $?$ & - & $?$ \\
\hline Marderstein $2008 \dagger$ & + & $?$ & + & + & $?$ & + & + & $?$ & + & + & + \\
\hline Metcalf $1996 \dagger$ & + & + & + & + & + & + & + & - & + & + & + \\
\hline Miyoshi $2000 \dagger$ & $?$ & + & + & + & + & + & + & + & + & + & + \\
\hline Niv $1995+$ & - & + & + & $?$ & + & + & + & - & + & + & + \\
\hline Norrelund 1996 & + & $?$ & + & + & + & - & - & $?$ & $?$ & + & - \\
\hline Panzuto 2003 & + & + & + & + & - & - & - & - & + & + & - \\
\hline Pepin 2002 & $?$ & - & + & - & - & - & - & - & $?$ & $?$ & - \\
\hline Pye 1989 & $?$ & $?$ & + & $?$ & - & + & - & $?$ & $?$ & + & $?$ \\
\hline Pye 1990 & + & $?$ & + & + & - & + & - & $?$ & $?$ & $?$ & + \\
\hline Robertson 2006 & $?$ & + & + & $?$ & + & $?$ & $?$ & - & $?$ & + & $?$ \\
\hline Selvachandran 2002 & + & + & + & + & $?$ & $?$ & $?$ & $?$ & $?$ & + & + \\
\hline Shastri $2008 \dagger$ & $?$ & + & + & + & + & + & + & + & + & + & + \\
\hline Sieg $1998 \dagger$ & $?$ & + & + & + & $?$ & + & $?$ & + & + & + & + \\
\hline Sieg 1999† & $?$ & + & + & + & + & + & + & + & + & + & + \\
\hline Smith 2006 & $?$ & + & + & + & + & + & + & - & $?$ & $?$ & + \\
\hline Steine $1994 \dagger$ & $?$ & + & + & + & - & + & + & + & + & + & + \\
\hline Tan $2002 \dagger$ & + & + & + & + & + & + & + & $?$ & + & + & $?$ \\
\hline Tate 1988 & $?$ & + & + & $?$ & + & + & + & $?$ & + & + & $?$ \\
\hline Tate 1989 & + & $?$ & + & $?$ & - & + & - & $?$ & $?$ & - & + \\
\hline Tate 1990 & $?$ & + & + & $?$ & - & + & + & + & $?$ & + & + \\
\hline Thomas 1992 & $?$ & + & + & $?$ & - & + & - & $?$ & $?$ & + & + \\
\hline Thompson $2007 \dagger$ & + & $?$ & + & + & + & + & - & $?$ & + & + & + \\
\hline Thompson $2008 \dagger$ & + & $?$ & + & + & + & + & - & $?$ & + & + & + \\
\hline Wauters 2000 & + & + & + & - & + & $?$ & - & $?$ & $?$ & $?$ & + \\
\hline Zarchy 1991 & $?$ & + & + & + & - & + & + & $?$ & $?$ & + & $?$ \\
\hline Total & 18 & 30 & 40 & 28 & 20 & 29 & 18 & 7 & 19 & 38 & 30 \\
\hline
\end{tabular}

+=no bias; -=potential bias; ?=bias unclear.

*1=valid selection, representative patients, $2=$ blinded to reference standard, $3=$ index test not part of reference standard, $4=$ clinical data available as normal, $5=$ adequate reference test, $6=$ all $/$ random selection receive

reference test, $7=$ all received same test, $8=$ blinded to index test, $9=$ target condition did not change between tests, $10=$ no withdrawal, 11=no missing/uninterpretable data (see appendix B on bmj.com for full details of scoring).

†Study received positive assessment on at least eight of 11 quality items. diagnostic performance of age, family history, weight loss, individual signs and symptoms; combinations of symptoms, referral guidelines; blood tests (such as for anaemia); and faecal occult blood tests in diagnosing colorectal cancer in adult patients with symptoms.

\section{METHODS}

Data sources and searches

We searched PubMed and Embase for eligible diagnostic studies (all publications to September 2008). The search strategy used MeSH/EMTREE terms and free text words, and included subsearches related to the study population, index test, target condition, and publication type. We added a methodological filter to increase the specificity of the search. This sensitive filter was created by combining three filters for the identification of diagnostic studies via the Boolean operator "OR". ${ }^{16-18}$

Reference lists of all retrieved primary diagnostic studies were checked for additional relevant diagnostic studies. Additionally, we checked references of relevant reviews, meta-analyses, guidelines, and commentaries identified in PubMed and Embase.

\section{Study selection}

Two authors (PJ, DvdW) independently applied the predefined selection criteria. PJ checked all citations (titles and abstracts) identified by the search strategy, while DvdW checked eligibility of all citations assessed by $\mathrm{PJ}$ as (possibly) relevant. Consensus meetings were organised to discuss any disagreement regarding selection. Full publications were retrieved for studies that seemed relevant, and for those for which relevance was still unclear. A third review author (DB) was consulted in cases of persisting disagreement.

\section{Participants, setting, and study design}

We considered studies eligible if the study population consisted of adult patients consulting a physician with non-acute lower abdominal symptoms. Therefore, population based or screening studies - that is, studies that include people without abdominal symptomswere excluded. We defined "non-acute" as being present for at least two weeks. ${ }^{19}$ Although primary care is the setting of interest, in some countries primary care is not well defined. Therefore, we decided to additionally include studies performed at the interface between primary and secondary care, such as two week referral clinics and open access outpatient clinics. In open access clinics, patients' characteristics and the spectrum of disease might resemble those found in primary care populations. As not all publications clearly reported whether or not an outpatient clinic was directly accessible to patients, however, we decided to select only those secondary care studies with a prevalence of colorectal cancer of less than $15 \%$. By using this criterion, which was the highest prevalence reported in the primary care studies, we tried to minimise the risk of bias from diagnostic pre-selection. Studies with hospital inpatients were also excluded. 


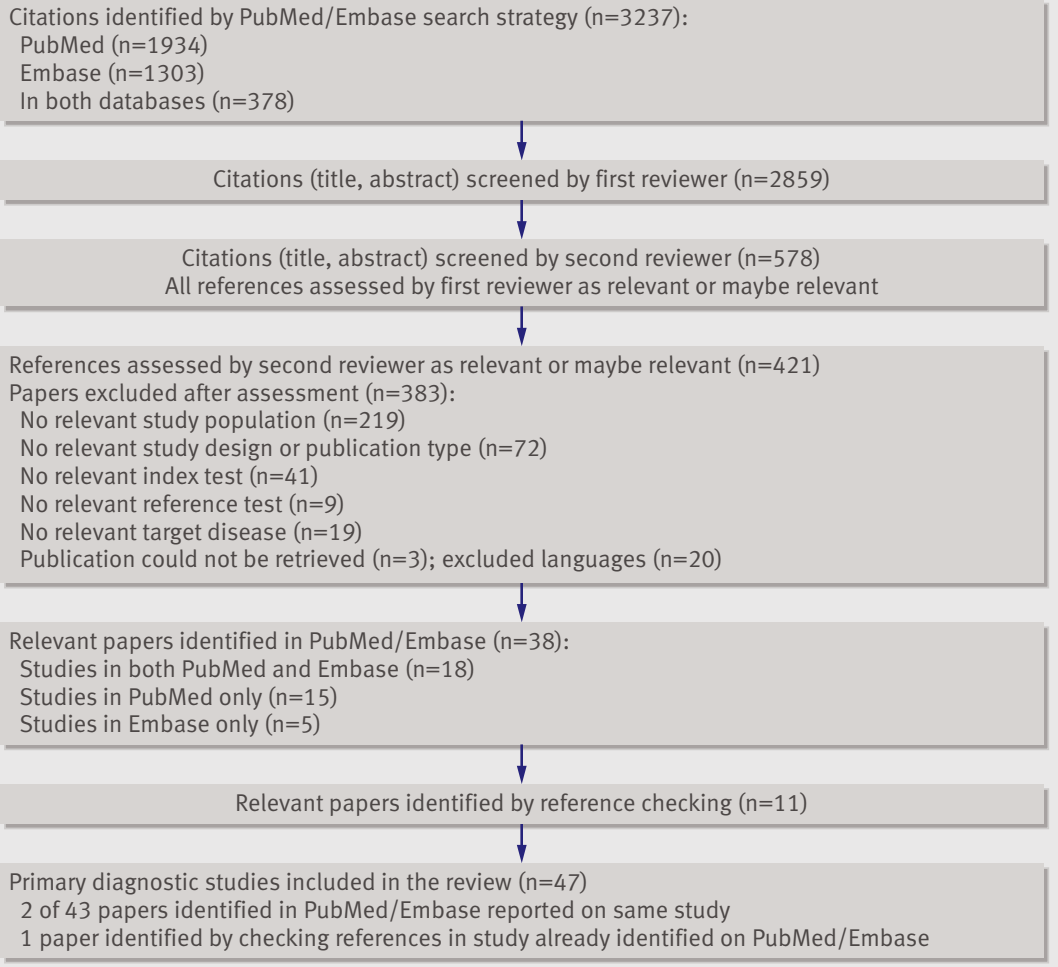

Fig $1 \mid$ Results of search strategy and selection procedure

We included primary diagnostic studies with a cohort design and case-control designs in which controls formed a representative sample of all patients with abdominal symptoms. We excluded studies for which we could not extract or reconstruct two by two tables, studies written in a language other than English, Dutch, German, or French, and reviews, editorials, and case reports.

\section{Reference test}

We included studies that used colonoscopy, barium enema, or clinical follow-up as reference standards to diagnose or exclude colorectal cancer. Studies that used sigmoidoscopy as the single reference test were excluded.

\section{Index test}

We included studies on tests that can be carried out or are usually accessible in primary care, specifically age, family history, weight loss, individual signs and symptoms; combinations of symptoms, including referral guidelines; blood tests; and faecal occult blood tests. Studies reporting data only on main indications for colonoscopy were excluded as they ignore the presence of additional symptoms. As ultrasonography is not commonly used in primary care we excluded this test.

\section{Data collection and quality assessment}

The reviewers extracted data on setting and design, study population, test characteristics, and test results. Methodological quality was assessed with a modified version of the quality assessment of diagnostic accuracy studies (QUADAS) tool, ${ }^{20}$ which is recommended by the Cochrane Diagnostic Reviewers' Handbook. ${ }^{21}$ This modified version consists of 11 items on methodological characteristics that have the potential to introduce bias (see appendix $\mathrm{B}$ on bmj.com). Items were scored as positive (no bias), negative (potential bias), or unclear.

Two reviewers assessed each paper: $\mathrm{PJ}$ extracted data from all studies while $\mathrm{HdV}$, DvdW, and DB each extracted data from a third of the studies, independently from each other and using a standardised form. Agreement between observers was quantified and disagreements were resolved by consensus meetings.

As recommended by the designers of the QUADAS tool we did not apply weights to the QUADAS items or use a summary score in the analysis. Instead, we used subgroup analyses to explore whether scores on the following quality items explained variation in diagnostic performance: item 1 (validity of study sample), item 2 (test review bias), item 5 (validity of reference standard), and item 7 (differential verification bias). These items have been shown to result in biased estimates of diagnostic performance in empirical studies. ${ }^{223}$

\section{Data synthesis and statistical analysis}

We examined diagnostic two by two tables and diagnostic performance measures per study (sensitivity, specificity, predictive values). We also looked at study results by setting.

Positive predictive values (PPV) and the reverse of negative predictive values $(1-\mathrm{NPV})$, represent the probability of colorectal cancer in patients with a positive or negative test result, respectively. These measures provide a clear indication of the diagnostic value of a test - that is, the extent to which the prior probability of colorectal cancer is modified by either a positive or a negative test result. To illustrate results of relevant diagnostic tests we present forest plots of PPV and 1-NPV.

We used MetaDiSc statistical software to calculate diagnostic performance measures and corresponding $95 \%$ confidence intervals. ${ }^{1324}$ When four or more studies on a specific index test showed sufficient clinical and statistical homogeneity, we used bivariate analyse ${ }^{25}$ to calculate pooled estimates and $95 \%$ confidence intervals for the summary estimates of sensitivity and specificity, and of positive and negative predictive values. The bivariate analyses take into account variability within and between studies and the dependency between either sensitivity and specificity or positive and negative predictive values. Bivariate analyses based on a random effect model perform better than SROC regression models derived with the Moses and Littenberg method, which departs from a fixed effects model. ${ }^{26}$ We defined statistical heterogeneity as non-overlapping confidence intervals for estimates of diagnostic parameters and a difference in these estimates among the studies of more than $20 \%$. When assessing heterogeneity we always simultaneously considered sensitivity and specificity (or PPV and 1-NPV). In case of statistical or considerable 
Table 2 |Summary of findings (sensitivity, specificity, predictive values) for tests studied by at least four primary diagnostic studies, with medians in case of heterogeneity and pooled estimates ( $95 \%$ confidence intervals) in case of homogeneity

\begin{tabular}{|c|c|c|c|c|c|c|c|c|c|}
\hline \multirow{2}{*}{$\begin{array}{l}\text { Index test } \\
\text { and setting }\end{array}$} & \multirow{2}{*}{$\begin{array}{c}\text { No of } \\
\text { studies }\end{array}$} & \multicolumn{2}{|c|}{ Sensitivity } & \multicolumn{2}{|c|}{ Specificity } & \multicolumn{2}{|c|}{ Postitve test result } & \multicolumn{2}{|c|}{ Negative test result } \\
\hline & & Range & Median/pooled & Range & Median/pooled & Risk & Median/pooled & Risk & Median/pooled \\
\hline \multicolumn{10}{|c|}{ Non-gastrointestinal risk factors, individual signs and symptoms } \\
\hline \multicolumn{10}{|l|}{ Age $>50 v<50$} \\
\hline Primary care & 2 & $0.86-0.96$ & \multirow{2}{*}{0.91} & $0.39-0.46$ & \multirow{2}{*}{0.36} & $0.06-0.11$ & \multirow{2}{*}{$0.10(0.07$ to 0.13$)$} & 0.01-0.01 & \multirow{2}{*}{$0.02(0.01$ to 0.03$)$} \\
\hline Secondary care & 4 & $0.81-0.96$ & & $0.30-0.66$ & & $0.08-0.19$ & & $0.01-0.07$ & \\
\hline \multicolumn{10}{|l|}{ Age $>60 v<60$} \\
\hline Primary care & 3 & $0.73-0.93$ & \multirow{2}{*}{0.83} & $0.52-0.88$ & \multirow{2}{*}{0.55} & $0.05-0.20$ & \multirow{2}{*}{0.09 (0.08 to 0.10$)^{-}$} & $0.00-0.02$ & \multirow{2}{*}{$0.02(0.01$ to 0.02$)$} \\
\hline Secondary care & 4 & $0.50-0.85$ & & $0.48-0.84$ & & $0.08-0.10$ & & $0.02-0.03$ & \\
\hline Age $>70 v<70$ & & & & & & & & & \\
\hline Primary care & 3 & $0.36-0.63$ & & $0.72-0.83$ & & $0.08-0.31$ & & $0.03-0.08$ & \\
\hline Secondary care & 1 & 0.25 & 0.50 & 0.94 & 0.79 & 0.12 & 0.13 & 0.03 & 0.03 \\
\hline Sex: male $v$ female & & & & & & & & & \\
\hline Primary care & 4 & $0.44-0.78$ & & $0.46-0.57$ & & $0.05-0.17$ & & $0.01-0.13$ & \\
\hline TWR clinic & 1 & 0.71 & 0.62 & 0.61 & 0.55 & 0.16 & $0.07(0.05$ to 0.12$)$ & 0.05 & $0.04(0.02$ to 0.07$)$ \\
\hline Secondary care & 4 & $0.37-0.70$ & & $0.52-0.57$ & & $0.01-0.16$ & & $0.02-0.08$ & \\
\hline Family history & & & & & & & & & \\
\hline Primary care & 2 & $0.00-0.13$ & & $0.86-0.91$ & & $0.00-0.10$ & & $0.09-0.11$ & \\
\hline Secondary care & 4 & $0.00-1.00$ & 0.16 & $0.75-0.98$ & 0.91 & $0.00-0.13$ & 0.06 & $0.00-0.05$ & 0.04 \\
\hline Weight loss & & & & & & & & & \\
\hline Primary care & 6 & $0.13-0.44$ & & $0.85-0.94$ & & $0.05-0.23$ & & $0.02-0.13$ & \\
\hline TWR clinic & 1 & 0.14 & 0.20 & 0.72 & 0.89 & 0.05 & 0.09 & 0.11 & 0.06 \\
\hline Secondary care & 6 & $0.15-0.37$ & & $0.79-0.96$ & & $0.05-0.36$ & & $0.01-0.11$ & \\
\hline Palpable mass* & & & & & & & & & \\
\hline Primary care & 2 & $0.11-0.22$ & & $0.89-0.96$ & & $0.04-0.32$ & & $0.04-0.06$ & \\
\hline TWR clinic & 2 & $0.06-0.25$ & - & 0.94-0.99 & - & $0.16-0.80$ & - & $0.08-0.13$ & - \\
\hline Secondary care & 1 & 0.04 & & 0.97 & & 0.08 & & 0.06 & \\
\hline Abdominal pain & & & & & & & & & \\
\hline Primary care & 6 & $0.00-0.40$ & & $0.49-0.91$ & & $0.00-0.23$ & & $0.05-0.12$ & \\
\hline TWR clinic & 1 & 0.21 & 0.35 & 0.57 & 0.59 & 0.05 & 0.05 & 0.13 & 0.07 \\
\hline Secondary care & 13 & $0.00-0.73$ & & $0.19-0.84$ & & $0.00-0.15$ & & $0.01-0.21$ & \\
\hline Rectal bleeding & & & & & & & & & \\
\hline Secondary care & 13 & $0.25-0.86$ & 0.44 & $0.31-0.88$ & 0.66 & $0.03-0.21$ & 0.07 (0.05 to 0.10$)$ & $0.01-0.14$ & 0.04 (0.03 to 0.06$)$ \\
\hline All bleeding, dark & od & & & & & & & & \\
\hline Primary care & 4 & $0.25-0.41$ & & $0.69-0.87$ & & $0.07-0.17$ & & $0.03-0.10$ & \\
\hline Secondary care & 1 & 0.35 & 0.35 & 0.90 & 0.85 & 0.20 & $0.14(0.09 \text { to } 0.21)^{-}$ & 0.05 & $0.05(0.03$ to 0.07$)$ \\
\hline All bleeding, mixec & vith stool & & & & & & & & \\
\hline Primary care & 4 & 0.09-0.77 & 0.51 & $0.49-0.95$ & 0.71 & $0.03-0.14$ & $0.06(0.04$ to 0.10$)$ & $0.01-0.06$ & $0.03(0.01$ to 0.05$)$ \\
\hline Change in bowel $\mathrm{h}$ & it present & absent & & & & & & & \\
\hline Primary care & 6 & $0.10-1.00$ & & $0.55-0.93$ & & $0.05-0.50$ & & $0.00-0.39$ & \\
\hline Secondary care & 12 & $0.06-0.86$ & 0.52 & $0.28-0.94$ & 0.61 & $0.03-0.27$ & 0.09 & $0.02-0.15$ & 0.04 \\
\hline Diarrhoea present & absent & & & & & & & & \\
\hline Primary care & 1 & 0.25 & & 0.73 & & 0.07 & & 0.08 & \\
\hline Secondary care & $4 \dagger$ & $0.06-0.24$ & 0.20 (0.14 to 0.29$)$ & $0.65-0.79$ & $0.73(0.67 \text { to } 0.78)^{-}$ & $0.01-0.14$ & $-0.06(0.02 \text { to } 0.15)^{-}$ & $0.05-0.16$ & $0.10(0.07$ to 0.14$)$ \\
\hline Constipation & & & & & & & & & \\
\hline Primary care & 1 & 0.13 & & 0.58 & & 0.03 & & 0.12 & \\
\hline Secondary care & 3 & $0.00-0.51$ & 0.13 & $0.53-0.90$ & 0.12 & $0.00-0.16$ & $0.06(0.02$ to 0.18$)$ & $0.03-0.14$ & $0.09(0.05$ to 0.15$)$ \\
\hline Peri-anal symptom & & & & & & & & & \\
\hline Primary care & 3 & $0.25-0.36$ & & $0.22-0.95$ & & $0.02-0.18$ & & $0.02-0.17$ & \\
\hline Secondary care & 2 & $0.36-0.56$ & - & $0.39-0.40$ & - & $0.03-0.04$ & - & $0.05-0.08$ & - \\
\hline Symptom combina & ons, inclu & ng referral g & delines & & & & & & \\
\hline TWR guidelines po & ive $v$ neg & & & & & & & & \\
\hline TWR clinic & 4 & $0.86-0.92$ & & $0.30-0.54$ & & $0.12-0.25$ & & $0.02-0.04$ & \\
\hline Secondary care & $1 \S$ & $0.80-0.94$ & 0.92 & $0.54-0.56$ & 0.42 & $0.08-0.14$ & 0.14 & $0.01-0.02$ & 0.03 \\
\hline
\end{tabular}




\begin{tabular}{|c|c|c|c|c|c|c|c|c|c|}
\hline \multirow{2}{*}{$\begin{array}{l}\text { Index test } \\
\text { and setting }\end{array}$} & \multirow{2}{*}{$\begin{array}{c}\text { No of } \\
\text { studies }\end{array}$} & \multicolumn{2}{|c|}{ Sensitivity } & \multicolumn{2}{|c|}{ Specificity } & \multicolumn{2}{|c|}{ Postitve test result } & \multicolumn{2}{|c|}{ Negative test result } \\
\hline & & Range & Median/pooled & Range & Median/pooled & Risk & Median/pooled & Risk & Median/pooled \\
\hline
\end{tabular}

Positive $v$ negative result on test for iron deficiency anaemia

\begin{tabular}{|c|c|c|c|c|c|c|c|c|c|}
\hline TWR clinic & 2 & $0.09-0.20$ & \multirow{2}{*}{0.13} & $0.92-0.94$ & \multirow{2}{*}{0.92} & $0.11-0.34$ & \multirow{2}{*}{0.13} & 0.09-0.12 & \multirow{2}{*}{0.08} \\
\hline Secondary care & 6 & $0.07-0.68$ & & $0.83-0.95$ & & $0.04-0.41$ & & $0.01-0.11$ & \\
\hline
\end{tabular}

Faecal occult blood tests

Positive $v$ negative result on guaiac based tests

\begin{tabular}{|c|c|c|c|c|c|c|c|c|c|}
\hline Primary care & $1 \rrbracket$ & 0.57 & \multirow{2}{*}{0.75} & 0.90 & \multirow{2}{*}{0.86} & 0.18 & \multirow{2}{*}{0.28} & 0.02 & \multirow{2}{*}{0.01} \\
\hline Secondary care & 13 & $0.33-1.00$ & & $0.72-0.94$ & & $0.07-0.59$ & & $0.00-0.07$ & \\
\hline \multicolumn{10}{|c|}{ Positive $v$ negative result on immunological based tests } \\
\hline Secondary care & 8 & $0.70-1.00$ & 0.95 & $0.71-0.93$ & 0.84 & $0.07-0.59$ & 0.21 & $0.00-0.05$ & 0.00 \\
\hline
\end{tabular}

TWR=two week referral.

* Summary of findings not presented as some studies included rectal mass as index test while others included abdominal mass.

†Excludes study of Pepin et al because of inclusion criterion "constipation."

¥Summary of findings not presented as studies included different types of peri-anal symptoms (for example, anal itch, haemorrhoids).

$\S$ Excludes study by Selvachandran et al because they used abridged version of two week referral TWR guideline;

TExcludes study by Fijten et al because of inclusion criterion "rectal bleeding."

clinical heterogeneity (in terms of characteristics of populations or tests) we refrained from pooling and presented median values and ranges instead.

\section{Investigations of heterogeneity}

Factors that can contribute to variation in diagnostic performance across studies (heterogeneity) include differences in (a) setting (primary care $v$ primary-secondary care interface $v$ secondary care); (b) prevalence of CRC $(<5 \% v \geq 5 \%)$, (c) tumour location (rectum $v$ other left sided (sigmoid, colon descendens, flexura lienalis) $v$ right sided (rest)); (d) cancer type (Dukes's A and B v Dukes's C and D); (e1) faecal occult blood tests (guaiac $v$ immunochemical); (e2) guaiac based faecal occult blood tests (dietary restrictions $v$ no restrictions); (e3): guaiac based faecal occult blood tests (self test $v$ regular test); (f) QUADAS items 1, 2, 5, or 7 (as described above). Subgroup analyses (a), (b), (e1), (e2), and (f) concern analyses between study subgroups, while (c), (d), (e1), and (e3) concern analyses within studies.

Subgroup analyses were performed only when each subgroup included data of at least four diagnostic studies. In case of statistical homogeneous results for both sensitivity and specificity per subgroup, we calculated pooled estimates using bivariate analyses. In case of

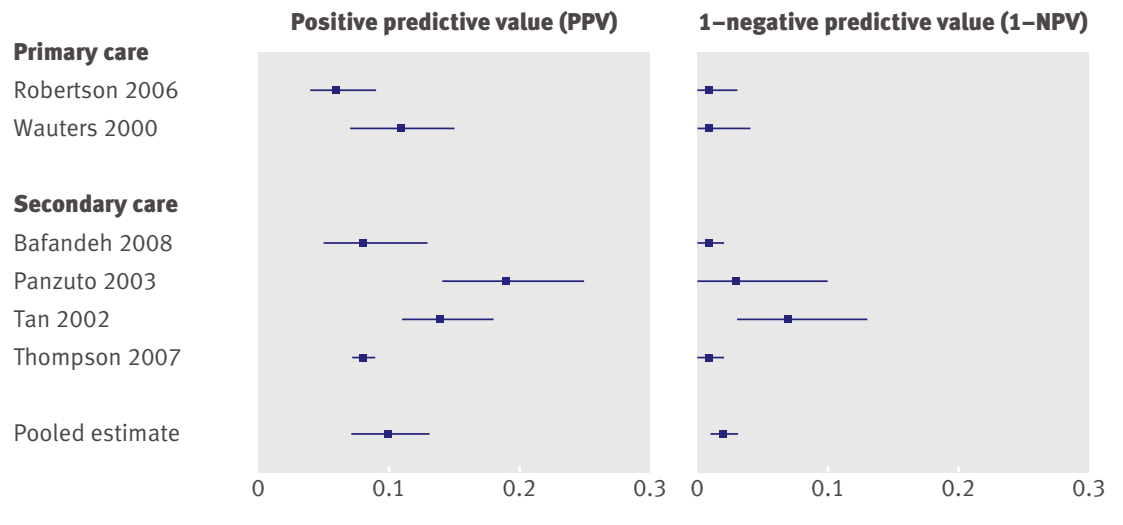

Fig 2 | Risk of colorectal cancer in patients aged $\geq 50$ (positive predictive value) versus risk in patients $<50$ (1-negative predictive value) statistical heterogeneous results, we presented the range of sensitivity and specificity per subgroup. Studies that provided insufficient information on a factor could not be included in that specific subgroup analysis.

\section{RESULTS}

\section{Literature search and study selection}

The literature search yielded 2859 references. A total of 421 full papers were retrieved, of which 38 were finally considered relevant for the review. ${ }^{11227-62}$ Reference checking yielded 11 additional relevant papers. ${ }^{863-72}$ As four papers ${ }^{8293072}$ presented information on two studies, our total number of primary diagnostic studies for inclusion was 47. Figure 1 summarises the search results.

\section{Study characteristics}

Full details of the 47 included studies are in appendix $\mathrm{C}$ on bmj.com. All studies were cohort studies on patients with abdominal symptoms. Nine studies took place in primary care, with the prevalence of colorectal cancer ranging from $3 \%$ to $15 \% .^{313334404449616370}$ Signs and symptoms were the main index tests in these studies. Seven studies used rectal bleeding as the inclusion criterion. $^{33344044496170}$ Five studies were performed at the interface between primary and secondary care, with prevalence of colorectal cancer ranging from $9 \%$ to $14 \%{ }^{2865-68}$ Three studies included individual referral criteria as the index test ${ }^{286568}$; four studies used the referral guideline itself (that is, combination of criteria). ${ }^{65-68}$ Of the 33 studies in secondary care, 20 were performed in diagnostic clinics (colonoscopy, ${ }^{827323637394143454650-535571}$ double contrast barium enema ${ }^{54576264}$ ) and 13 in outpatient clinics. ${ }^{11122935384247485658-6069}$ Prevalence of colorectal cancer ranged from $0.4 \%$ to $15 \%$.

\section{Quality assessment}

On average, the reviewers disagreed in three out of 11 items (range 1-6 across studies). Table 1 presents the results of the quality assessment after consensus. 
Table 3 | Diagnostic performance of age and sex in diagnosis of colorectal cancer

\begin{tabular}{|c|c|c|c|c|c|c|c|c|}
\hline Index test and setting & TP & FP & $\mathrm{FN}$ & TN & $\begin{array}{l}\text { Sensitivity } \\
(95 \% \mathrm{Cl})\end{array}$ & $\begin{array}{l}\text { Specificity } \\
(95 \% \mathrm{Cl})\end{array}$ & $\begin{array}{l}\text { Risk with positive test } \\
\text { result }(95 \% \mathrm{Cl})\end{array}$ & $\begin{array}{l}\text { Risk with negative test } \\
\text { result }(95 \% \mathrm{Cl})\end{array}$ \\
\hline \multicolumn{9}{|l|}{ Age } \\
\hline \multicolumn{9}{|c|}{$\geq 50 v<50$, all bleeding, primary care } \\
\hline Robertson 2006 & 19 & 315 & 3 & 267 & 0.86 (0.65 to 0.97$)$ & $0.46(0.42$ to 0.50$)$ & 0.06 (0.04 to 0.09$)$ & $0.01(0.00$ to 0.03$)$ \\
\hline Wauters 2000 & 26 & 219 & 1 & 140 & 0.96 (0.81 to 1.00$)$ & $0.39(0.34$ to 0.44$)$ & $0.11(0.07$ to 0.15$)$ & $0.01(0.00$ to 0.04$)$ \\
\hline \multicolumn{9}{|c|}{$\geq 60 v<60$, all bleeding, primary care } \\
\hline Ellis 2005 & 8 & 147 & 3 & 161 & $0.73(0.39$ to 0.94$)$ & $0.52(0.47$ to 0.58$)$ & 0.05 (0.02 to 0.10$)$ & $0.02(0.00$ to 0.05$)$ \\
\hline Fijten 1995 & 8 & 32 & 1 & 228 & $0.89(0.52$ to 1.00$)$ & $0.88(0.83$ to 0.91$)$ & 0.20 (0.09 to 0.36$)$ & $0.00(0.00$ to 0.02$)$ \\
\hline Wauters 2000 & 25 & 163 & 2 & 196 & 0.93 (0.76 to 0.99$)$ & $0.55(0.49$ to 0.60$)$ & 0.13 (0.09 to 0.19$)$ & 0.01 (0.00 to 0.04$)$ \\
\hline \multicolumn{9}{|c|}{$\geq 70 v<70$, all bleeding, primary care } \\
\hline Robertson 2006 & 8 & 99 & 14 & 483 & $0.36(0.17$ to 0.59$)$ & $0.83(0.80$ to 0.86$)$ & $0.08(0.03$ to 0.14$)$ & $0.03(0.02$ to 0.05$)$ \\
\hline Wauters 2000 & 17 & 100 & 10 & 259 & $0.63(0.42$ to 0.81$)$ & $0.72(0.67$ to 0.77$)$ & 0.15 (0.09 to 0.22$)$ & $0.04(0.02$ to 0.07$)$ \\
\hline Norrelund 1996 & 34 & 76 & 20 & 234 & 0.63 (0.49 to 0.76$)$ & $0.76(0.70$ to 0.80$)$ & $0.31(0.22$ to 0.40$)$ & $0.08(0.05$ to 0.12$)$ \\
\hline \multicolumn{9}{|c|}{$\geq 80 v<80$, all bleeding, primary care } \\
\hline Wauters 2000 & 3 & 48 & 24 & 311 & $0.11(0.02$ to 0.29$)$ & $0.87(0.83$ to 0.90$)$ & $0.06(0.01$ to 0.16$)$ & $0.07(0.05$ to 0.11$)$ \\
\hline \multicolumn{9}{|l|}{$\geq 40 v<40$, secondary care } \\
\hline Selvachandran 2002 & 93 & 1809 & 2 & 364 & 0.98 (0.93 to 1.00$)$ & $0.17(0.15$ to 0.18$)$ & 0.05 (0.04 to 0.06$)$ & 0.01 (0.00 to 0.02$)$ \\
\hline Thompson 2007 & 462 & 6736 & 5 & 1326 & 0.99 (0.98 to 0.99$)$ & $0.16(0.16$ to 0.17$)$ & $0.06(0.06$ to 0.07$)$ & $0.00(0.00$ to 0.01$)$ \\
\hline \multicolumn{9}{|l|}{$\geq 50 v<50$, secondary care } \\
\hline Bafandeh 2008 & 14 & 156 & 2 & 308 & 0.88 (0.62 to 0.98$)$ & $0.66(0.62$ to 0.71$)$ & 0.08 (0.05 to 0.13$)$ & 0.01 (0.00 to 0.02$)$ \\
\hline Panzuto 2003 & 39 & 168 & 2 & 71 & 0.95 (0.84 to 0.99 ) & $0.30(0.24$ to 0.36$)$ & 0.19 (0.14 to 0.25$)$ & 0.03 (0.00 to 0.10$)$ \\
\hline Tan 2002 & 47 & 286 & 11 & 141 & 0.81 (0.69 to 0.90$)$ & $0.33(0.29$ to 0.38$)$ & 0.14 (0.11 to 0.18$)$ & $0.07(0.04$ to 0.13$)$ \\
\hline Thompson 2007 & 449 & 5497 & 18 & 2565 & 0.96 (0.94 to 0.98$)$ & $0.32(0.31$ to 0.33$)$ & $0.08(0.07$ to 0.08$)$ & $0.01(0.00$ to 0.01$)$ \\
\hline \multicolumn{9}{|l|}{$\geq 60 v<60$, secondary care } \\
\hline Bafandeh 2008 & 8 & 74 & 8 & 390 & $0.50(0.25$ to 0.75$)$ & 0.84 (0.80 to 0.87$)$ & $0.10(0.04$ to 0.18$)$ & 0.02 (0.01 to 0.04$)$ \\
\hline Bjerregaard 2007 & 90 & 1076 & 32 & 974 & $0.74(0.65$ to 0.81$)$ & $0.48(0.45$ to 0.50$)$ & 0.09 (0.06 to 0.09$)$ & $0.03(0.02$ to 0.05$)$ \\
\hline Selvachandran $2002^{*}$ & 130 & 1425 & 26 & 1721 & 0.83 (0.77 to 0.89$)$ & $0.55(0.53$ to 0.57$)$ & $0.08(0.07$ to 0.10$)$ & $0.02(0.01$ to 0.02$)$ \\
\hline Thompson 2007 & 396 & 4017 & 71 & 4045 & 0.85 (0.81 to 0.88$)$ & $0.50(0.49$ to 0.51$)$ & 0.09 (0.08 to 0.10$)$ & 0.02 (0.01 to 0.02$)$ \\
\hline \multicolumn{9}{|l|}{$\geq 65 v<65$, secondary care } \\
\hline Zarchy 1991 & 13 & 255 & 10 & 516 & $0.57(0.35$ to 0.77$)$ & $0.67(0.64$ to 0.70$)$ & 0.05 (0.03 to 0.08$)$ & $0.02(0.01$ to 0.04$)$ \\
\hline \multicolumn{9}{|l|}{$\geq 70 v<70$, secondary care } \\
\hline Bafandeh 2008 & 4 & 30 & 12 & 434 & 0.25 (0.07 to 0.52$)$ & 0.94 (0.91 to 0.96$)$ & 0.12 (0.03 to 0.28$)$ & 0.03 (0.01 to 0.05$)$ \\
\hline \multicolumn{9}{|l|}{$\geq 80 v<80$, secondary care } \\
\hline Thompson 2007 & 100 & 715 & 367 & 7347 & 0.21 (0.18 to 0.25$)$ & $0.91(0.91$ to 0.92$)$ & $0.12(0.10$ to 0.15$)$ & 0.05 (0.04 to 0.05$)$ \\
\hline \multicolumn{9}{|l|}{ Sex male $v$ female } \\
\hline \multicolumn{9}{|l|}{ All bleeding, primary care } \\
\hline Fijten 1995 & 7 & 111 & 2 & 149 & 0.78 ( 0.40 to 0.97$)$ & $0.57(0.51$ to 0.63$)$ & $0.06(0.02$ to 0.12$)$ & 0.01 (0.00 to 0.05$)$ \\
\hline Mant 1989 & 7 & 70 & 9 & 59 & $0.44(0.20$ to 0.70$)$ & $0.46(0.37$ to 0.55$)$ & 0.09 (0.04 to 0.18$)$ & $0.13(0.06$ to 0.24$)$ \\
\hline Norrelund 1996 & 29 & 139 & 25 & 171 & $0.54(0.40$ to 0.67$)$ & 0.55 (0.49 to 0.61$)$ & $0.17(0.12$ to 0.24$)$ & $0.13(0.08$ to 0.18$)$ \\
\hline Robertson 2006 & 13 & 260 & 9 & 322 & 0.59 (0.36 to 0.79$)$ & $0.55(0.51$ to 0.59$)$ & 0.05 (0.03 to 0.08$)$ & $0.03(0.01$ to 0.05$)$ \\
\hline \multicolumn{9}{|l|}{ Two week referral clinic } \\
\hline Barwick 2004 & 10 & 51 & 4 & 79 & 0.71 (0.42 to 0.92$)$ & $0.61(0.52$ to 0.69$)$ & $0.16(0.08$ to 0.28$)$ & 0.05 (0.01 to 0.12$)$ \\
\hline \multicolumn{9}{|l|}{ Secondary care } \\
\hline Selvachandran $2002^{*}$ & 98 & 1421 & 58 & 1725 & 0.63 (0.55 to 0.70$)$ & $0.55(0.53$ to 0.57$)$ & 0.07 (0.05 to 0.08$)$ & 0.03 (0.02 to 0.04$)$ \\
\hline Tan 2002 & 36 & 185 & 22 & 242 & 0.62 (0.48 to 0.74$)$ & $0.57(0.52$ to 0.61$)$ & $0.16(0.12$ to 0.22$)$ & 0.08 (0.05 to 0.12$)$ \\
\hline Zarchy 1991 & 16 & 363 & 7 & 408 & 0.70 (0.47 to 0.87$)$ & $0.53(0.49$ to 0.56$)$ & $0.04(0.02$ to 0.07$)$ & 0.02 (0.01 to 0.03$)$ \\
\hline \multicolumn{9}{|c|}{ All constipated, secondary care } \\
\hline Pepin 2002 & 3 & 267 & 5 & 288 & 0.37 (0.08 to 0.75$)$ & $0.52(0.48$ to 0.56$)$ & 0.01 (0.00 to 0.03$)$ & $0.02(0.01$ to 0.04$)$ \\
\hline
\end{tabular}

TP=true positives; $\mathrm{FP}=$ false positives; $\mathrm{FN}=$ false negatives; $\mathrm{TN}=$ true negatives.

${ }^{*}$ For this study we extracted data for some index tests from more recent paper of Hodder et al. ${ }^{72}$

Potential sources of bias most frequently identified concerned an invalid reference standard (item 5) and differential verification bias (item 7). Valid selection and representativeness of study populations (item 1), blind interpretation of results of the reference standard (item
$8)$, and length of the period between index test and reference standard (item 9) were poorly described (that is, score unclear). Generally, 12 studies performed well, receiving a positive assessment of at least eight out of 11 QUADAS items. ${ }^{2741-4350-525455596070}$ 
Table 4 | Diagnostic performance of family history and weight loss in diagnosis of colorectal cance

\begin{tabular}{|c|c|c|c|c|c|c|c|c|}
\hline Index test and setting & TP & FP & $\mathrm{FN}$ & TN & $\begin{array}{l}\text { Sensitivity } \\
(95 \% \mathrm{Cl})\end{array}$ & $\begin{array}{l}\text { Specificity } \\
(95 \% \mathrm{Cl})\end{array}$ & $\begin{array}{l}\text { Risk with positive test } \\
\text { result }(95 \% \mathrm{Cl})\end{array}$ & $\begin{array}{l}\text { Risk with negative test } \\
\text { result }(95 \% \mathrm{Cl})\end{array}$ \\
\hline \multicolumn{9}{|l|}{ Family history } \\
\hline \multicolumn{9}{|c|}{ All bleeding, 1 st degree relative with colorectal cancer, primary care } \\
\hline Mant 1989 & 2 & 18 & 14 & 109 & $0.13(0.02$ to 0.38$)$ & $0.86(0.79$ to 0.91$)$ & 0.10 (0.01 to 0.32$)$ & 0.11 (0.06 to 0.18$)$ \\
\hline \multicolumn{9}{|l|}{ Family history, primary care } \\
\hline Metcalf 1996 & 0 & 8 & 8 & 83 & 0.00 (0.00 to 0.37$)$ & $0.91(0.83$ to 0.96$)$ & 0.00 (0.00 to 0.37$)$ & 0.09 (0.04 to 0.17$)$ \\
\hline \multicolumn{9}{|c|}{ Family history of cancer, secondary care } \\
\hline Bafandeh 2008 & 0 & 10 & 16 & 454 & $0.00(0.00$ to 0.21$)$ & 0.98 (0.96 to 0.99$)$ & 0.00 (0.00 to 0.31$)$ & $0.03(0.02$ to 0.06$)$ \\
\hline \multicolumn{9}{|c|}{ 1st degree relative $>50$ with colorectal cancer, secondary care } \\
\hline Bjerregaard 2007 & 23 & 183 & 99 & 1867 & $0.19(0.12$ to 0.27$)$ & $0.91(0.90$ to 0.92$)$ & 0.11 (0.07 to 0.16$)$ & 0.05 (0.04 to 0.06$)$ \\
\hline \multicolumn{9}{|c|}{ One or two 1 st degree relatives with colorectal cancer, secondary care } \\
\hline Charalambopoulos 2000 & 3 & 200 & 0 & 592 & $1.00(0.29$ to 1.00$)$ & $0.75(0.72$ to 0.78$)$ & 0.02 (0.00 to 0.04$)$ & 0.00 (0.00 to 0.01$)$ \\
\hline \multicolumn{9}{|c|}{ All constipated, family history, secondary care } \\
\hline Pepin 2002 & 2 & 14 & 6 & 541 & 0.25 (0.03 to 0.65$)$ & 0.98 (0.96 to 0.99$)$ & $0.13(0.02$ to 0.38$)$ & 0.01 (0.00 to 0.02$)$ \\
\hline \multicolumn{9}{|l|}{ Weight loss } \\
\hline \multicolumn{9}{|l|}{ All bleeding, primary care } \\
\hline Fijten 1995 & 4 & 38 & 5 & 222 & 0.44 (0.14 to 0.79$)$ & 0.85 (0.81 to 0.89$)$ & 0.10 (0.03 to 0.23$)$ & 0.02 (0.01 to 0.05$)$ \\
\hline Mant 1989 & 2 & 12 & 14 & 115 & 0.13 (0.02 to 0.38$)$ & 0.91 (0.84 to 0.95$)$ & 0.14 (0.02 to 0.43$)$ & 0.11 (0.06 to 0.18$)$ \\
\hline Metcalf 1996 & 2 & 13 & 6 & 78 & 0.25 (0.03 to 0.65$)$ & 0.86 (0.77 to 0.92$)$ & 0.13 (0.02 to 0.41$)$ & 0.07 (0.03 to 0.15$)$ \\
\hline Norrelund 1996 & 10 & 34 & 40 & 266 & $0.20(0.10$ to 0.34$)$ & 0.89 (0.85 to 0.92$)$ & 0.23 (0.12 to 0.38$)$ & 0.13 (0.10 to 0.17$)$ \\
\hline Robertson 2006 & 3 & 59 & 19 & 512 & 0.14 (0.03 to 0.35$)$ & 0.90 (0.87 to 0.92$)$ & 0.05 (0.01 to 0.14$)$ & 0.04 (0.02 to 0.06$)$ \\
\hline Wauters 2000 & 4 & 21 & 23 & 338 & 0.15 (0.04 to 0.34$)$ & 0.94 (0.91 to 0.96$)$ & $0.16(0.05$ to 0.36$)$ & 0.06 (0.04 to 0.09$)$ \\
\hline \multicolumn{9}{|l|}{ Two week referral clinic } \\
\hline Barwick 2004 & 2 & 36 & 12 & 94 & 0.14 (0.02 to 0.43$)$ & $0.72(0.64$ to 0.80$)$ & 0.05 (0.01 to 0.18$)$ & 0.11 (0.06 to 0.19$)$ \\
\hline \multicolumn{9}{|l|}{ Secondary care } \\
\hline Selvachandran 2002 & 17 & 163 & 78 & 2010 & $0.18(0.11$ to 0.27$)$ & $0.93(0.91$ to 0.94$)$ & 0.09 (0.06 to 0.15$)$ & $0.04(0.03$ to 0.05$)$ \\
\hline Steine 1994 & 17 & 335 & 38 & 1450 & 0.31 (0.19 to 0.45$)$ & $0.81(0.79$ to 0.83$)$ & 0.05 (0.03 to 0.08$)$ & $0.03(0.02$ to 0.04$)$ \\
\hline Zarchy 1991 & 4 & 52 & 19 & 719 & 0.17 (0.05 to 0.39$)$ & 0.93 (0.91 to 0.95$)$ & 0.07 (0.02 to 0.17$)$ & 0.03 (0.02 to 0.04$)$ \\
\hline Bjerregaard 2007 & 26 & 426 & 96 & 1624 & 0.21 (0.14 to 0.30$)$ & $0.79(0.77$ to 0.81$)$ & 0.06 (0.04 to 0.08$)$ & 0.06 (0.05 to 0.07$)$ \\
\hline \multicolumn{9}{|c|}{ Loss $>3 \mathrm{~kg}$ in past 3 months, secondary care } \\
\hline Panzuto 2003 & 15 & 27 & 26 & 212 & 0.37 (0.22 to 0.53$)$ & 0.89 (0.84 to 0.92$)$ & $0.36(0.22$ to 0.52$)$ & $0.11(0.07$ to 0.16$)$ \\
\hline \multicolumn{9}{|l|}{ Loss $\geq 3 \mathrm{~kg}$, secondary care } \\
\hline Bjerregaard 2007 & 18 & 321 & 104 & 1729 & 0.15 (0.09 to 0.22$)$ & $0.84(0.83$ to 0.86$)$ & 0.05 (0.03 to 0.08$)$ & $0.06(0.05$ to 0.07$)$ \\
\hline Pepin 2002 & 2 & 25 & 6 & 530 & $0.25(0.03$ to 0.65$)$ & $0.96(0.93$ to 0.97$)$ & 0.07 (0.01 to 0.24$)$ & 0.01 (0.00 to 0.02$)$ \\
\hline
\end{tabular}

Diagnostic performance of individual characteristics

Table 2 summarises the findings, including the results of tests that have been studied by at least four primary diagnostic studies.

Age, sex, family history, and weight loss

Results for age and sex are summarised in table 3 and for family history and weight loss in table 4 . For age, sensitivity and specificity were strongly dependent on the cut-off value; the lower the cut-off score (such as age $\geq 40$ ), the higher sensitivity and the lower specificity. ${ }^{82729333444454955596162}$ Figure 2 shows the PPV and $1-N P V$ using a cut-off of $\geq 50$ for age. Pooled estimates (six studies) showed that patients aged $\geq 50$ had a $10 \%$ risk of colorectal cancer $(95 \%$ confidence interval $7 \%$ to $13 \%$, while patients aged $<50$ had a risk of $2 \%(1 \%$ to $3 \%)$. There is a sharp decrease in sensitivity with a cut-off for age of $\geq 70$ compared with a cut-off of age $\geq 60$ (median 0.50 and 0.83 , respectively) (table 2). For sex (male) sensitivity ranged from 0.37 to 0.78 , while specificity ranged from 0.46 to 0.57 (table 3). ${ }^{82834404446495562}$ The risk for colorectal cancer in men is somewhat higher than in women $(0.07$ $v 0.04$ ), but confidence intervals overlap (table 2). For family history (present) $)^{2727292932324046466270}$ and

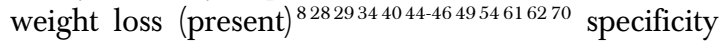
seemed to be rather consistent and high (medians 0.91 and 0.89 , respectively) (tables 2 and 4 ). Sensitivity, however, ranged from 0.00 to 1.00 for family history and from 0.13 to 0.44 for weight loss. For all four factors visual inspection showed no differences between the different settings of care.

\section{Signs}

Five studies reported on the diagnostic performance of a palpable mass (table 5). ${ }^{2934616568}$ Sensitivity ranged from 0.04 (abdominal tumour) to 0.25 (rectal mass), while specificity ranged from 0.89 to 0.99 (rectal mass). In the study of Flashman et al general practitioners identified in the same cohort of patients many 
Table 5|Diagnostic performance of abdominal signs and symptoms in diagnosis of colorectal cancer

\begin{tabular}{|c|c|c|c|c|c|c|c|c|}
\hline Index test and setting & TP & FP & $\mathrm{FN}$ & TN & $\begin{array}{l}\text { Sensitivity } \\
(95 \% \mathrm{Cl})\end{array}$ & $\begin{array}{l}\text { Specificity } \\
(95 \% \mathrm{Cl})\end{array}$ & $\begin{array}{l}\text { Risk with positive test result } \\
\qquad(95 \% \mathrm{Cl})\end{array}$ & $\begin{array}{l}\text { Risk with negative } \\
\text { test result }(95 \% \mathrm{Cl})\end{array}$ \\
\hline \multicolumn{9}{|l|}{ Signs } \\
\hline \multicolumn{9}{|c|}{ All bleeding, palpable rectal mass, primary care } \\
\hline Fijten 1995 & 1 & 22 & 8 & 177 & 0.11 (0.00 to 0.48$)$ & 0.89 (0.84 to 0.93$)$ & $0.04(0.00$ to 0.22$)$ & $0.04(0.02$ to 0.08$)$ \\
\hline Wauters 2000 & 6 & 13 & 21 & 346 & 0.22 (0.09 to 0.42$)$ & $0.96(0.94$ to 0.98$)$ & $0.32(0.13$ to 0.57$)$ & 0.06 (0.04 to 0.09$)$ \\
\hline \multicolumn{9}{|c|}{ Abdominal mass*, two week referral clinic } \\
\hline Chohan 2005 & 7 & 10 & 57 & 388 & 0.11 (0.05 to 0.21$)$ & 0.98 (0.95 to 0.99$)$ & 0.41 (0.18 to 0.67$)$ & 0.13 (0.10 to 0.16$)$ \\
\hline \multicolumn{9}{|c|}{ Palpable abdominal mass ${ }^{\star}$, right sided, two week referral clinic } \\
\hline Flashman 2004, GP findings & 7 & 36 & 58 & 594 & 0.11 (0.04 to 0.21$)$ & $0.94(0.92$ to 0.96$)$ & $0.16(0.07$ to 0.31$)$ & $0.09(0.07$ to 0.11$)$ \\
\hline $\begin{array}{l}\text { Flashman 2004, clinic } \\
\text { findings }\end{array}$ & 4 & 18 & 61 & 612 & $0.06(0.02$ to 0.15$)$ & 0.97 (0.96 to 0.98$)$ & $0.18(0.05$ to 0.40$)$ & 0.09 (0.07 to 0.12$)$ \\
\hline \multicolumn{9}{|c|}{ Rectal mass ${ }^{\star}$, two week referral clinic } \\
\hline Chohan 2005 & 16 & 4 & 48 & 394 & $0.25(0.15$ to 0.37$)$ & $0.99(0.97$ to 1.00$)$ & 0.80 (0.56 to 0.94$)$ & 0.11 (0.08 to 0.14$)$ \\
\hline \multicolumn{9}{|c|}{ Palpable rectal mass ${ }^{\star}$, not pelvic, two week referral clinic } \\
\hline Flashman 2004, GP findings & 12 & 41 & 53 & 589 & $0.19(0.10$ to 0.30$)$ & 0.94 (0.91 to 0.95$)$ & $0.23(0.12$ to 0.36$)$ & 0.08 (0.06 to 0.11$)$ \\
\hline Flashman 2004, clinic & 13 & 15 & 52 & 615 & $0.20(0.11$ to 0.32$)$ & $0.98(0.96$ to 0.99$)$ & $0.46(0.28$ to 0.66$)$ & 0.08 (0.06 to 0.10$)$ \\
\hline
\end{tabular}

findings

Abdominal tumour, secondary care

\begin{tabular}{lllllllll}
\hline Bjerregaard 2007 & 5 & 56 & 117 & 1994 & $0.04(0.01$ to 0.09$)$ & $0.97(0.97$ to 0.98$)$ & $0.08(0.03$ to 0.18$)$ & $0.06(0.05$ to 0.07$)$ \\
\hline
\end{tabular}

Abdominal pain

All bleeding, abdominal pain, primary care

\begin{tabular}{|c|c|c|c|c|c|c|c|c|}
\hline Fijten 1995 & 3 & 132 & 6 & 128 & 0.33 (0.08 to 0.70$)$ & 0.49 (0.43 to 0.56$)$ & 0.02 (0.01 to 0.06$)$ & $0.05(0.02$ to 0.10$)$ \\
\hline Mant 1989 & 4 & 39 & 12 & 89 & 0.25 (0.07 to 0.52$)$ & 0.70 (0.61 to 0.77$)$ & 0.09 (0.03 to 0.22$)$ & $0.12(0.06$ to 0.20$)$ \\
\hline Metcalf 1996 & 3 & 39 & 5 & 52 & $0.38(0.09$ to 0.76$)$ & 0.57 (0.46 to 0.68$)$ & $0.07(0.02$ to 0.20$)$ & $0.09(0.03$ to 0.19$)$ \\
\hline Norrelund 1996 & 21 & 69 & 31 & 234 & $0.40(0.27$ to 0.55$)$ & 0.77 (0.72 to 0.82$)$ & $0.23(0.15$ to 0.33$)$ & $0.12(0.08$ to 0.16$)$ \\
\hline Robertson 2006 & 4 & 228 & 16 & 342 & 0.20 (0.06 to 0.44$)$ & 0.60 (0.56 to 0.64$)$ & $0.02(0.00$ to 0.04$)$ & $0.05(0.03$ to 0.07$)$ \\
\hline Wauters 2000 & 0 & 34 & 27 & 325 & 0.00 (0.00 to 0.13$)$ & 0.91 (0.87 to 0.93$)$ & $0.00(0.00$ to 0.10$)$ & $0.08(0.05$ to 0.11$)$ \\
\hline \multicolumn{9}{|c|}{ Abdominal pain, two week referral clinic } \\
\hline Barwick 2004 & 3 & 56 & 11 & 74 & 0.21 (0.05 to 0.51$)$ & 0.57 (0.48 to 0.66$)$ & 0.05 (0.01 to 0.14$)$ & 0.13 (0.07 to 0.22$)$ \\
\hline \multicolumn{9}{|c|}{ Abdominal pain, secondary care } \\
\hline Bafandeh 2008 & 7 & 140 & 9 & 324 & $0.44(0.20$ to 0.70$)$ & $0.70(0.65$ to 0.74$)$ & $0.05(0.02$ to 0.10$)$ & $0.03(0.01$ to 0.05$)$ \\
\hline Bjerregaard 2007 & 57 & 1116 & 65 & 934 & $0.47(0.38$ to 0.56$)$ & $0.46(0.43$ to 0.48$)$ & 0.05 (0.04 to 0.06$)$ & $0.07(0.05$ to 0.08$)$ \\
\hline Brewster 1994 & 0 & 81 & 21 & 360 & 0.00 (0.00 to 0.16$)$ & 0.82 (0.78 to 0.85$)$ & 0.00 (0.00 to 0.05$)$ & $0.06(0.03$ to 0.08$)$ \\
\hline Farrands 1995 & 2 & 85 & 11 & 41 & 0.15 (0.02 to 0.45$)$ & 0.33 (0.25 to 0.42$)$ & 0.02 (0.00 to 0.08$)$ & 0.21 (0.11 to 0.35$)$ \\
\hline Panzuto 2003 & 30 & 193 & 11 & 46 & $0.73(0.57$ to 0.86$)$ & 0.19 (0.14 to 0.25$)$ & 0.14 (0.09 to 0.19$)$ & $0.19(0.10$ to 0.32$)$ \\
\hline Selvachandran 2002 & 33 & 1196 & 62 & 977 & $0.35(0.25$ to 0.45$)$ & $0.45(0.43$ to 0.47$)$ & $0.03(0.02$ to 0.04$)$ & $0.06(0.05$ to 0.08$)$ \\
\hline Steine 1994 & 27 & 1269 & 28 & 508 & 0.49 (0.35 to 0.63$)$ & $0.29(0.27$ to 0.31$)$ & 0.02 (0.01 to 0.03$)$ & 0.05 (0.04 to 0.08$)$ \\
\hline Tan 2002 & 21 & 117 & 37 & 310 & $0.36(0.24$ to 0.50$)$ & 0.73 (0.68 to 0.77$)$ & 0.15 (0.10 to 0.22$)$ & $0.11(0.08$ to 0.14$)$ \\
\hline Tate 1988 & 3 & 43 & 11 & 73 & 0.21 (0.05 to 0.51$)$ & 0.63 (0.54 to 0.72$)$ & 0.07 (0.01 to 0.18$)$ & 0.13 (0.07 to 0.22$)$ \\
\hline Thompson 2007 & 206 & 3557 & 261 & 4505 & 0.44 (0.40 to 0.49$)$ & $0.56(0.56$ to 0.57$)$ & $0.06(0.05$ to 0.06$)$ & $0.06(0.05$ to 0.06$)$ \\
\hline Thompson 2008 & 311 & 7042 & 635 & 8445 & $0.33(0.30$ to 0.36$)$ & $0.55(0.54$ to 0.55$)$ & 0.04 (0.04 to 0.05$)$ & 0.07 (0.07 to 0.08$)$ \\
\hline Zarchy 1991 & 11 & 307 & 12 & 464 & $0.48(0.27$ to 0.69$)$ & $0.60(0.57$ to 0.64$)$ & $0.04(0.02$ to 0.06$)$ & $0.03(0.01$ to 0.04$)$ \\
\hline \multicolumn{9}{|c|}{ Abdominal pain as only symptom, secondary care } \\
\hline Thompson 2008 & 12 & 900 & 934 & 14587 & 0.01 (0.01 to 0.02$)$ & 0.94 (0.94 to 0.95$)$ & 0.01 (0.01 to 0.02$)$ & $0.06(0.06$ to 0.06$)$ \\
\hline \multicolumn{9}{|c|}{ All constipated, abdominal pain, secondary care } \\
\hline Pepin 2002 & 4 & 89 & 4 & 466 & 0.50 (0.16 to 0.84$)$ & 0.84 (0.81 to 0.87$)$ & 0.04 (0.01 to 0.11$)$ & $0.01(0.00$ to 0.02$)$ \\
\hline \multicolumn{9}{|c|}{ All bleeding, spasms, primary care } \\
\hline Wauters 2000 & 6 & 105 & 21 & 254 & $0.22(0.09$ to 0.42$)$ & $0.71(0.66$ to 0.75$)$ & $0.05(0.02$ to 0.11$)$ & $0.08(0.05$ to 0.11$)$ \\
\hline
\end{tabular}

$\mathrm{TP}=$ true positives; $\mathrm{FP}=$ false positives; $\mathrm{FN}=$ false negatives; $\mathrm{TN}=$ true negatives.

*Two week referral criterion.

more palpable abdominal or rectal masses than clinicians in the clinic (43v22 and $53 v 28$, respectively). ${ }^{68}$ Of the 43 patients identified by the general practitioner as having an abdominal mass, seven $(16 \%)$ were diagnosed with colorectal cancer compared with four of the $22(18 \%)$ identified in the clinic. Of the 53 patients identified by the general practitioner as having a rectal mass, $12(23 \%)$ were diagnosed with colorectal cancer compared with 13 of 28 $(46 \%)$ identified in the clinic. 


\section{Table 6 | Diagnostic performance of rectal bleeding in diagnosis of colorectal cancer}

\begin{tabular}{|c|c|c|c|c|c|c|c|c|}
\hline Index test and setting & TP & FP & $\mathrm{FN}$ & TN & $\begin{array}{l}\text { Sensitivity } \\
(95 \% \mathrm{Cl})\end{array}$ & $\begin{array}{l}\text { Specificity } \\
(95 \% \mathrm{Cl})\end{array}$ & $\begin{array}{l}\text { Risk with positive test } \\
\text { result }(95 \% \mathrm{Cl})\end{array}$ & $\begin{array}{l}\text { Risk with negative test } \\
\text { result }(95 \% \mathrm{Cl})\end{array}$ \\
\hline \multicolumn{9}{|c|}{ Rectal bleeding, secondary care } \\
\hline Bafandeh 2008 & 4 & 138 & 12 & 326 & 0.25 (0.07 to 0.52$)$ & $0.70(0.66$ to 0.74$)$ & $0.03(0.01$ to 0.07$)$ & $0.04(0.02$ to 0.06$)$ \\
\hline Bjerregaard 2007 & 83 & 1090 & 39 & 960 & 0.68 (0.59 to 0.76$)$ & $0.47(0.45$ to 0.49$)$ & 0.07 (0.06 to 0.09$)$ & $0.04(0.03$ to 0.05$)$ \\
\hline Brewster 1994 & 9 & 150 & 12 & 291 & $0.43(0.22$ to 0.66$)$ & $0.66(0.61$ to 0.70$)$ & $0.06(0.03$ to 0.11$)$ & $0.04(0.02$ to 0.07$)$ \\
\hline Farrands 1995 & 5 & 62 & 8 & 64 & 0.39 (0.14 to 0.68$)$ & $0.51(0.42$ to 0.60$)$ & $0.08(0.03$ to 0.17$)$ & $0.11(0.05$ to 0.21$)$ \\
\hline Panzuto 2003 & 18 & 96 & 23 & 143 & $0.44(0.29$ to 0.60$)$ & $0.60(0.53$ to 0.66$)$ & $0.16(0.10$ to 0.24$)$ & 0.14 (0.09 to 0.20$)$ \\
\hline Selvachandran 2002 & 82 & 1505 & 13 & 668 & 0.86 (0.78 to 0.93$)$ & $0.31(0.29$ to 0.33$)$ & $0.05(0.04$ to 0.06$)$ & $0.02(0.01$ to 0.03$)$ \\
\hline Steine 1994 & 17 & 271 & 37 & 1498 & 0.32 (0.20 to 0.46$)$ & 0.85 (0.83 to 0.86$)$ & $0.06(0.04$ to 0.09$)$ & $0.02(0.02$ to 0.03$)$ \\
\hline Tan 2002 & 33 & 121 & 25 & 306 & 0.57 (0.43 to 0.70$)$ & $0.72(0.67$ to 0.76$)$ & $0.21(0.15$ to 0.29$)$ & $0.08(0.05$ to 0.11$)$ \\
\hline Tate 1988 & 9 & 40 & 5 & 76 & 0.64 (0.35 to 0.87$)$ & $0.66(0.56$ to 0.74$)$ & 0.18 (0.09 to 0.32$)$ & $0.06(0.02$ to 0.14$)$ \\
\hline Thompson 2007 & 333 & 5079 & 134 & 2983 & 0.71 (0.67 to 0.75$)$ & $0.37(0.36$ to 0.38$)$ & $0.06(0.06$ to 0.07$)$ & 0.04 (0.04 to 0.05$)$ \\
\hline Thompson 2008 & 624 & 9841 & 322 & 5646 & $0.66(0.63$ to 0.69$)$ & $0.37(0.36$ to 0.37$)$ & $0.06(0.06$ to 0.06$)$ & $0.05(0.05$ to 0.06$)$ \\
\hline Zarchy 1991 & 8 & 222 & 15 & 549 & 0.35 (0.16 to 0.57$)$ & $0.71(0.68$ to 0.74$)$ & $0.04(0.02$ to 0.07$)$ & $0.03(0.02$ to 0.04$)$ \\
\hline \multicolumn{9}{|c|}{ Rectal bleeding as only symptom, secondary care } \\
\hline Thompson 2008 & 105 & 4128 & 841 & 11359 & 0.11 (0.09 to 0.13$)$ & $0.73(0.73$ to 0.74$)$ & $0.02(0.02$ to 0.03$)$ & $0.07(0.07$ to 0.07$)$ \\
\hline \multicolumn{9}{|c|}{ All constipated, bleeding overt, secondary care } \\
\hline Pepin 2002 & 2 & 66 & 6 & 489 & $0.25(0.03$ to 0.65$)$ & $0.88(0.85$ to 0.91$)$ & $0.03(0.00$ to 0.10$)$ & $0.01(0.00$ to 0.03$)$ \\
\hline \multicolumn{9}{|c|}{ All bleeding, dark blood, primary care } \\
\hline Ellis 2005 & 3 & 28 & 8 & 191 & 0.27 (0.06 to 0.61$)$ & $0.87(0.82$ to 0.91$)$ & $0.10(0.02$ to 0.26$)$ & $0.04(0.02$ to 0.08$)$ \\
\hline Mant 1989 & 4 & 19 & 12 & 109 & 0.25 (0.07 to 0.52$)$ & $0.85(0.78$ to 0.91$)$ & $0.17(0.05$ to 0.39$)$ & $0.10(0.05$ to 0.17$)$ \\
\hline Metcalf 1996 & 3 & 28 & 5 & 63 & $0.38(0.09$ to 0.76$)$ & 0.69 (0.59 to 0.79$)$ & $0.10(0.02$ to 0.26$)$ & $0.07(0.02$ to 0.16$)$ \\
\hline Robertson 2006 & 9 & 112 & 13 & 470 & $0.41(0.21$ to 0.64$)$ & $0.81(0.77$ to 0.84$)$ & $0.07(0.04$ to 0.14$)$ & $0.03(0.01$ to 0.05$)$ \\
\hline \multicolumn{9}{|c|}{ All bleeding, dark blood, secondary care } \\
\hline Bjerregaard 2007 & 29 & 114 & 54 & 976 & $0.35(0.25$ to 0.46$)$ & $0.90(0.88$ to 0.91$)$ & $0.20(0.14$ to 0.28$)$ & $0.05(0.04$ to 0.07$)$ \\
\hline \multicolumn{9}{|c|}{ All bleeding, first episode, primary care } \\
\hline Ellis 2005 & 5 & 101 & 6 & 154 & $0.46(0.17$ to 0.77$)$ & $0.60(0.54$ to 0.66$)$ & $0.05(0.02$ to 0.11$)$ & $0.04(0.01$ to 0.08$)$ \\
\hline Fijten 1995 & 9 & 164 & 0 & 96 & $1.00(0.66$ to 1.00$)$ & $0.37(0.31$ to 0.43$)$ & $0.05(0.02$ to 0.10$)$ & $0.00(0.00$ to 0.04$)$ \\
\hline Norrelund 1996 & 45 & 271 & 9 & 39 & 0.83 (0.71 to 0.92$)$ & $0.13(0.09$ to 0.17$)$ & $0.14(0.11$ to 0.19$)$ & $0.19(0.09$ to 0.33$)$ \\
\hline \multicolumn{9}{|c|}{ All bleeding, mixed with stool, primary care } \\
\hline Ellis 2005 & 1 & 32 & 10 & 223 & 0.09 (0.00 to 0.41$)$ & $0.88(0.83$ to 0.91$)$ & $0.03(0.00$ to 0.16$)$ & $0.04(0.02$ to 0.08$)$ \\
\hline Metcalf 1996 & 5 & 41 & 3 & 50 & $0.63(0.25$ to 0.92$)$ & $0.55(0.44$ to 0.65$)$ & $0.11(0.04$ to 0.24$)$ & $0.06(0.01$ to 0.16$)$ \\
\hline Robertson 2006 & 17 & 297 & 5 & 285 & $0.77(0.55$ to 0.92$)$ & $0.49(0.45$ to 0.53$)$ & 0.05 (0.03 to 0.09$)$ & $0.02(0.01$ to 0.04$)$ \\
\hline \multicolumn{9}{|c|}{ All bleeding, solely mixed with stool, primary care } \\
\hline Fijten 1995 & 2 & 12 & 3 & 227 & $0.40(0.05$ to 0.85$)$ & 0.95 (0.91 to 0.97$)$ & $0.14(0.02$ to 0.43$)$ & $0.01(0.00$ to 0.04$)$ \\
\hline \multicolumn{9}{|c|}{ All bleeding, on paper only, primary care } \\
\hline Ellis 2005 & 2 & 80 & 9 & 175 & $0.18(0.02$ to 0.52$)$ & $0.69(0.63$ to 0.74$)$ & $0.02(0.00$ to 0.09$)$ & $0.05(0.02$ to 0.09$)$ \\
\hline Mant 1989 & 5 & 47 & 10 & 75 & 0.33 (0.12 to 0.62$)$ & $0.62(0.52$ to 0.70$)$ & 0.10 (0.03 to 0.21$)$ & $0.12(0.06$ to 0.21$)$ \\
\hline Metcalf 1996 & 2 & 22 & 6 & 69 & 0.25 (0.03 to 0.65$)$ & $0.76(0.66$ to 0.84$)$ & $0.08(0.01$ to 0.27$)$ & $0.08(0.03$ to 0.17$)$ \\
\hline
\end{tabular}

$\mathrm{TP}=$ true positives; $\mathrm{FP}=$ false positives; $\mathrm{FN}=$ false negatives; $\mathrm{TN}=$ true negatives.

\section{Symptoms}

Individual symptoms most commonly investigated included abdominal pain, rectal bleeding, (change in) bowel habit, and peri-anal symptoms. For abdominal pain $(20 \text { studies })^{8}{ }^{8227-29344044-4649545559-62647071}$ test results were heterogeneous with sensitivity ranging from 0.00 to 0.73 and specificity from 0.19 to 0.91 (table 2). In four of the 13 secondary care studies (table 5) the risk for colorectal cancer was significantly lower among those with abdominal pain than among those without. ${ }^{8125460}$

Table 6 shows data on rectal bleeding (13

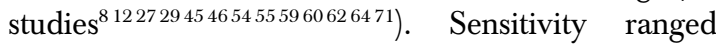
from 0.25 to 0.86 , while specificity ranged from 0.31 to 0.88 (table 2). Comparing the risk for colorectal cancer in those with a positive test result with those with a negative test result shows that patients with rectal bleeding, and also patients with blood mixed with stool have a somewhat higher risk (pooled estimates 0.07 and 0.06 , respectively) than those without (pooled estimates 0.04 and 0.03 , respectively) (table 2, fig 3). Confidence intervals, however, overlap each other. Patients with dark blood have a significantly higher risk than those without dark blood (pooled estimates $0.14,0.09$ to 0.21 , and $0.05,0.03$ to 0.07 , respectively) (table 2, fig 4).

Table 7 shows data on change in bowel habits (18 studies $^{81227293334404445495455596062647071}$ ). Results were heterogeneous with sensitivity ranging from 0.06 to 1.00 and specificity from 0.28 to 0.94 (table 2). For 
Table 7 | Diagnostic performance of change of bowel habit and peri-anal symptoms in diagnosis of colorectal cancer

\begin{tabular}{|c|c|c|c|c|c|c|c|c|}
\hline Index test and setting & TP & FP & FN & TN & Sensitivity $(95 \% \mathrm{Cl})$ & Specificity $(95 \% \mathrm{Cl})$ & $\begin{array}{l}\text { Risk with positive test result } \\
\qquad(95 \% \mathrm{Cl})\end{array}$ & $\begin{array}{l}\text { Risk with negative test result } \\
\qquad(95 \% \mathrm{Cl})\end{array}$ \\
\hline \multicolumn{9}{|l|}{ Bowel habit } \\
\hline \multicolumn{9}{|c|}{ All bleeding, change in bowel habit (CIBH) primary care } \\
\hline Ellis 2005 & 11 & 108 & 0 & 147 & $1.00(0.72$ to 1.00$)$ & $0.58(0.51$ to 0.64$)$ & $0.09(0.05$ to 0.16$)$ & $0.00(0.00$ to 0.03$)$ \\
\hline \multicolumn{9}{|c|}{ All bleeding, CIBH too loose/frequent, primary care } \\
\hline Ellis 2005 & 10 & 73 & 1 & 182 & $0.91(0.59$ to 1.00$)$ & $0.71(0.65$ to 0.77$)$ & $0.12(0.06$ to 0.21$)$ & $0.01(0.00$ to 0.03$)$ \\
\hline Fijten 1995 & 7 & 71 & 2 & 189 & 0.78 (0.40 to 0.97$)$ & 0.73 (0.67 to 0.78$)$ & $0.09(0.04$ to 0.18$)$ & 0.01 (0.00 to 0.04$)$ \\
\hline \multicolumn{9}{|c|}{ All bleeding, ClBH, primary care } \\
\hline Mant 1989 & 6 & 50 & 10 & 77 & $0.38(0.15$ to 0.65$)$ & $0.61(0.52$ to 0.69$)$ & 0.11 (0.04 to 0.22$)$ & 0.12 (0.06 to 0.20$)$ \\
\hline Metcalf 1996 & 4 & 4 & 35 & 56 & 0.10 (0.03 to 0.24$)$ & 0.93 (0.84 to 0.98$)$ & $0.50(0.16$ to 0.84$)$ & $0.39(0.28$ to 0.49$)$ \\
\hline Norrelund 1996 & 29 & 79 & 21 & 219 & $0.58(0.43$ to 0.72$)$ & 0.74 (0.68 to 0.78$)$ & $0.27(0.19$ to 0.36$)$ & 0.09 (0.06 to 0.13$)$ \\
\hline \multicolumn{9}{|c|}{ All bleeding, more frequent or looser stools, primary care } \\
\hline Robertson 2006 & 13 & 256 & 9 & 310 & 0.59 (0.36 to 0.79$)$ & 0.55 (0.51 to 0.59$)$ & 0.05 (0.03 to 0.08$)$ & $0.03(0.01$ to 0.05$)$ \\
\hline \multicolumn{9}{|c|}{ Change in bowel habit, secondary care } \\
\hline Bafandeh 2008 & 1 & 26 & 15 & 438 & 0.06 (0.00 to 0.30$)$ & 0.94 (0.92 to 0.96$)$ & $0.04(0.00$ to 0.19$)$ & $0.03(0.02$ to 0.05$)$ \\
\hline Brewster 1994 & 7 & 173 & 14 & 268 & 0.33 (0.15 to 0.57$)$ & 0.61 (0.56 to 0.65$)$ & 0.04 (0.02 to 0.08$)$ & 0.05 (0.03 to 0.08$)$ \\
\hline Farrands 1995 & 6 & 52 & 7 & 74 & 0.46 (0.19 to 0.75$)$ & 0.59 (0.50 to 0.67$)$ & $0.10(0.04$ to 0.21$)$ & $0.09(0.04$ to 0.17$)$ \\
\hline Selvachandran 2002 & 82 & 1573 & 13 & 600 & 0.86 (0.78 to 0.93$)$ & 0.28 (0.26 to 0.30$)$ & 0.05 (0.04 to 0.06$)$ & $0.02(0.01$ to 0.04$)$ \\
\hline Steine 1994 & 25 & 799 & 30 & 957 & $0.46(0.32$ to 0.59$)$ & 0.55 (0.52 to 0.57$)$ & 0.03 (0.02 to 0.04$)$ & 0.03 (0.02 to 0.04$)$ \\
\hline Tan 2002 & 8 & 87 & 50 & 340 & 0.14 (0.06 to 0.25$)$ & 0.80 (0.76 to 0.83$)$ & 0.08 (0.04 to 0.16$)$ & 0.13 (0.10 to 0.17$)$ \\
\hline Tate 1988 & 9 & 25 & 5 & 91 & 0.64 (0.35 to 0.87$)$ & 0.78 (0.70 to 0.86$)$ & 0.27 (0.13 to 0.44$)$ & 0.05 (0.02 to 0.12$)$ \\
\hline Thompson 2007 & 359 & 3527 & 108 & 4535 & 0.77 (0.73 to 0.81$)$ & 0.56 (0.55 to 0.57$)$ & 0.09 (0.08 to 0.10$)$ & 0.02 (0.02 to 0.03$)$ \\
\hline Thompson 2008 & 599 & 7439 & 347 & 8048 & 0.63 (0.60 to 0.66$)$ & $0.52(0.51$ to 0.53$)$ & 0.09 (0.07 to 0.08$)$ & 0.04 (0.04 to 0.05$)$ \\
\hline Zarchy 1991 & 7 & 223 & 16 & 548 & 0.30 (0.13 to 0.53$)$ & 0.71 (0.68 to 0.74$)$ & 0.03 (0.01 to 0.06$)$ & 0.03 (0.02 to 0.05$)$ \\
\hline \multicolumn{9}{|c|}{ Change in bowel habit in past 3 months, secondary care } \\
\hline Panzuto 2003 & 8 & 49 & 33 & 190 & $0.20(0.09$ to 0.35$)$ & 0.80 (0.74 to 0.84$)$ & 0.14 (0.06 to 0.26$)$ & $0.15(0.10$ to 0.20$)$ \\
\hline \multicolumn{9}{|c|}{ Change in bowel habit as only symptom, secondary care } \\
\hline Thompson 2008 & 65 & 1337 & 881 & 14150 & $0.07(0.05$ to 0.09$)$ & 0.91 (0.91 to 0.92$)$ & $0.05(0.04$ to 0.06$)$ & 0.06 (0.06 to 0.06$)$ \\
\hline \multicolumn{9}{|c|}{ Change in frequency of bowel movements, secondary care } \\
\hline Bjerregaard 2007 & 77 & 922 & 45 & 1128 & 0.63 (0.54 to 0.72$)$ & 0.55 (0.53 to 0.57$)$ & 0.08 (0.06 to 0.10$)$ & 0.04 (0.03 to 0.05$)$ \\
\hline \multicolumn{9}{|c|}{ Change in stool consistency, secondary care } \\
\hline Bjerregaard 2007 & 77 & 1061 & 45 & 989 & 0.63 (0.54 to 0.72$)$ & $0.48(0.46$ to 0.50$)$ & 0.07 (0.05 to 0.08$)$ & $0.04(0.03$ to 0.06$)$ \\
\hline \multicolumn{9}{|c|}{ All bleeding, diarrhoea, primary care } \\
\hline Metcalf 1996 & 2 & 25 & 6 & 66 & 0.25 (0.03 to 0.65$)$ & $0.73(0.62$ to 0.81$)$ & $0.07(0.01$ to 0.24$)$ & $0.08(0.03$ to 0.17$)$ \\
\hline \multicolumn{9}{|l|}{ Diarrhoea, secondary care } \\
\hline Badandeh 2008 & 1 & 163 & 15 & 301 & 0.06 (0.00 to 0.30$)$ & 0.65 (0.60 to 0.69$)$ & 0.01 (0.00 to 0.03$)$ & 0.05 (0.03 to 0.08$)$ \\
\hline Panzuto 2003 & 10 & 75 & 31 & 164 & 0.24 (0.12 to 0.40$)$ & $0.69(0.62$ to 0.74$)$ & $0.12(0.06$ to 0.21$)$ & 0.16 (0.11 to 0.22$)$ \\
\hline Tan 2002 & 14 & 89 & 44 & 338 & 0.24 (0.14 to 0.37$)$ & $0.79(0.75$ to 0.83$)$ & $0.14(0.08$ to 0.22$)$ & $0.12(0.09$ to 0.15$)$ \\
\hline Tate 1988 & 2 & 25 & 12 & 91 & 0.14 (0.02 to 0.43$)$ & $0.78(0.70$ to 0.86$)$ & $0.07(0.01$ to 0.24$)$ & $0.12(0.06$ to 0.20$)$ \\
\hline \multicolumn{9}{|c|}{ All constipated, diarrhoea, secondary care } \\
\hline Pepin 2002 & 2 & 20 & 6 & 535 & $0.25(0.03$ to 0.65$)$ & $0.96(0.95$ to 0.98$)$ & 0.09 (0.01 to 0.29$)$ & 0.01 (0.00 to 0.02$)$ \\
\hline \multicolumn{9}{|c|}{ All bleeding, constipation, primary care } \\
\hline Metcalf 1996 & 1 & 38 & 7 & 53 & $0.13(0.00$ to 0.53$)$ & 0.58 (0.47 to 0.69$)$ & $0.03(0.00$ to 0.14$)$ & $0.12(0.05$ to 0.23$)$ \\
\hline Constipation, secondary & & & & & & & & \\
\hline Badandeh 2008 & 2 & 46 & 14 & 418 & 0.13 (0.02 to 0.38$)$ & 0.90 (0.87 to 0.93$)$ & $0.04(0.00$ to 0.14$)$ & $0.03(0.02$ to 0.05$)$ \\
\hline Panzuto 2003 & 21 & 113 & 20 & 126 & 0.51 (0.35 to 0.67$)$ & 0.53 (0.46 to 0.59$)$ & $0.16(0.10$ to 0.23$)$ & 0.14 (0.09 to 0.20$)$ \\
\hline Tate 1988 & 0 & 16 & 14 & 100 & 0.00 (0.00 to 0.23$)$ & 0.86 (0.79 to 0.92$)$ & $0.00(0.00$ to 0.21$)$ & $0.12(0.07$ to 0.20$)$ \\
\hline Peri-anal symptoms & & & & & & & & \\
\hline All bleeding, peri-anal sy & nary c & & & & & & & \\
\hline Ellis 2005 & 4 & 199 & 7 & 56 & $0.36(0.11$ to 0.69$)$ & 0.22 (0.17 to 0.28$)$ & $0.02(0.01$ to 0.05$)$ & 0.11 (0.05 to 0.22$)$ \\
\hline All bleeding, anal (peri-) & nary ca & & & & & & & \\
\hline Fijten 1995 & 3 & 14 & 6 & 246 & 0.33 (0.08 to 0.70$)$ & 0.95 (0.91 to 0.97$)$ & 0.18 (0.04 to 0.43$)$ & 0.02 (0.01 to 0.05$)$ \\
\hline All bleeding, anal itch, p & & & & & & & & \\
\hline Mant 1989 & 1 & 35 & 15 & 94 & 0.06 (0.00 to 0.30$)$ & 0.73 (0.64 to 0.80$)$ & $0.03(0.03$ to 0.15$)$ & 0.14 (0.08 to 0.22$)$ \\
\hline All bleeding, anal protrus & care & & & & & & & \\
\hline Mant 1989 & 1 & 29 & 15 & 100 & 0.06 (0.00 to 0.30$)$ & 0.78 (0.69 to 0.84$)$ & 0.03 (0.00 to 0.17$)$ & $0.13(0.08$ to 0.21$)$ \\
\hline All bleeding, haemorrhoi & & & & & & & & \\
\hline Mant 1989 & 4 & 70 & 12 & 59 & 0.25 (0.07 to 0.52$)$ & 0.46 (0.37 to 0.55$)$ & 0.05 (0.02 to 0.13$)$ & 0.17 (0.09 to 0.28$)$ \\
\hline Peri-anal symptoms, sec & & & & & & & & \\
\hline Selvachandran 2002 & 53 & 1319 & 42 & 854 & 0.56 (0.45 to 0.66$)$ & 0.39 (0.37 to 0.41$)$ & 0.04 (0.03 to 0.05$)$ & 0.05 (0.03 to 0.06$)$ \\
\hline Thompson 2007 & 169 & 4831 & 298 & 3231 & $0.36(0.32$ to 0.41$)$ & $0.40(0.39$ to 0.41$)$ & $0.03(0.03$ to 0.04$)$ & 0.08 (0.08 to 0.09$)$ \\
\hline
\end{tabular}

TP=true positives; $F P=$ false positives; $F N=$ false negatives; $T N=$ true negatives. 
Table 8 Diagnostic performance of various gastrointestinal symptoms (other than those detailed in tables 3-7) in diagnosis of colorectal cance

\begin{tabular}{|c|c|c|c|c|c|c|c|c|}
\hline Index test and setting & TP & FP & $\mathrm{FN}$ & TN & Sensitivity $(95 \% \mathrm{Cl})$ & Specificity $(95 \% \mathrm{Cl})$ & $\begin{array}{l}\text { Risk with positive test } \\
\text { result }(95 \% \mathrm{Cl})\end{array}$ & $\begin{array}{l}\text { Risk with negative test } \\
\text { result }(95 \% \mathrm{Cl})\end{array}$ \\
\hline \multicolumn{9}{|l|}{ Urgency, secondary care } \\
\hline Selvachandran 2002 & 38 & 530 & 57 & 1643 & $0.40(0.30$ to 0.51$)$ & $0.76(0.74$ to 0.77$)$ & 0.07 (0.05 to 0.09$)$ & $0.03(0.03$ to 0.04$)$ \\
\hline \multicolumn{9}{|c|}{ Abdominal distension, secondary care } \\
\hline Steine 1994 & 36 & 1352 & 19 & 434 & $0.66(0.51$ to 0.78$)$ & $0.24(0.22$ to 0.26$)$ & $0.03(0.02$ to 0.04$)$ & $0.04(0.03$ to 0.07$)$ \\
\hline \multicolumn{9}{|l|}{ Bloating, secondary care } \\
\hline Panzuto 2003 & 22 & 147 & 19 & 92 & $0.54(0.37$ to 0.69$)$ & $0.39(0.32$ to 0.45$)$ & $0.13(0.08$ to 0.19$)$ & $0.17(0.11$ to 0.25$)$ \\
\hline \multicolumn{9}{|c|}{ All bleeding, incomplete evacuation, primary care } \\
\hline Mant 1989 & 5 & 37 & 11 & 92 & $0.31(0.11$ to 0.59$)$ & $0.71(0.63$ to 0.79$)$ & $0.12(0.04$ to 0.26$)$ & 0.11 (0.06 to 0.18$)$ \\
\hline \multicolumn{9}{|c|}{ Incomplete evacuation, secondary care } \\
\hline Selvachandran 2002 & 47 & 827 & 48 & 1346 & $0.50(0.39$ to 0.60$)$ & $0.62(0.60$ to 0.64$)$ & 0.05 (0.04 to 0.07$)$ & $0.03(0.03$ to 0.05$)$ \\
\hline Bjerregaard 2007 & 66 & 968 & 56 & 1082 & $0.54(0.45$ to 0.63$)$ & $0.53(0.51$ to 0.55$)$ & $0.06(0.05$ to 0.08$)$ & 0.05 (0.04 to 0.06$)$ \\
\hline \multicolumn{9}{|c|}{ All bleeding, associated slime, primary care } \\
\hline Metcalf 1996 & 3 & 25 & 5 & 66 & $0.38(0.09$ to 0.76$)$ & $0.73(0.62$ to 0.81$)$ & 0.11 (0.02 to 0.28$)$ & $0.07(0.02$ to 0.16$)$ \\
\hline \multicolumn{9}{|l|}{ Mucus, secondary care } \\
\hline Bjerregaard 2007 & 40 & 555 & 82 & 1495 & $0.33(0.25$ to 0.42$)$ & $0.73(0.71$ to 0.75$)$ & 0.07 (0.05 to 0.09$)$ & 0.05 (0.04 to 0.06$)$ \\
\hline \multicolumn{9}{|c|}{ Mucus alone, secondary care } \\
\hline Selvachandran 2002 & 16 & 416 & 79 & 1757 & $0.17(0.10$ to 0.26$)$ & 0.81 (0.79 to 0.83$)$ & $0.04(0.02$ to 0.06$)$ & 0.04 (0.03 to 0.05$)$ \\
\hline \multicolumn{9}{|c|}{ Mucus mixed with blood, secondary care } \\
\hline Selvachandran 2002 & 38 & 238 & 57 & 1935 & $0.40(0.30$ to 0.51$)$ & $0.89(0.88$ to 0.90$)$ & 0.14 (0.10 to 0.18$)$ & $0.03(0.02$ to 0.04$)$ \\
\hline \multicolumn{9}{|c|}{ All bleeding, painful defecation, primary care } \\
\hline Mant 1989 & 2 & 28 & 14 & 101 & $0.13(0.02$ to 0.38$)$ & $0.78(0.70$ to 0.85$)$ & 0.07 (0.01 to 0.22$)$ & $0.12(0.07$ to 0.20$)$ \\
\hline \multicolumn{9}{|c|}{ Painful defecation, secondary care } \\
\hline Selvachandran 2002 & 11 & 441 & 84 & 1732 & $0.12(0.06$ to 0.20$)$ & $0.80(0.78$ to 0.81$)$ & $0.02(0.01$ to 0.04$)$ & 0.05 (0.04 to 0.06$)$ \\
\hline \multicolumn{9}{|c|}{ All bleeding, pain at night, primary care } \\
\hline Fijten 1995 & 0 & 50 & 9 & 210 & $0.00(0.00$ to 0.34$)$ & $0.81(0.75$ to 0.85$)$ & $0.00(0.00$ to 0.07$)$ & $0.04(0.02$ to 0.08$)$ \\
\hline
\end{tabular}

eight studies confidence intervals for positive and negative test results did not overlap (table 2, fig 5), indicating that the risk for colorectal cancer was significantly higher among those with change in bowel habit than among those without. ${ }^{82933444596071}$ For diarrhoea (six studies) sensitivity ranged from 0.06 to 0.25 and

Bafandeh 2008

Bjerregaard 2007

Brewster 1994

Farrands 1995

Panzuto 2003

Selvachandran 2002

Steine 1994

Tan 2002

Tate 1988

Thompson 2007

Thompson 2008

Zarchy 1991

Pepin 2002

Pooled estimate
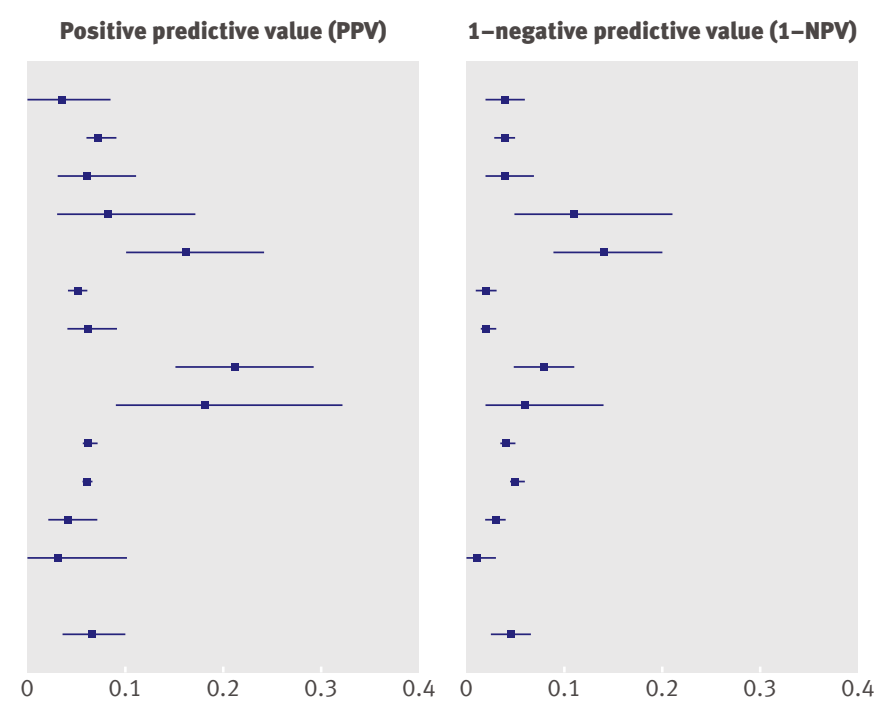

Fig 3| Risk of colorectal cancer in patients with rectal bleeding (positive predictive value) versus risk in those without rectal bleeding (1-negative predictive value); all studies conducted in secondary care specificity from 0.65 to $0.79,{ }^{2745557071}$ with the exception of the study of Pepin et al, ${ }^{46}$ with a specificity of 0.96 (table 7). That study, however, used constipation as inclusion criterion. For constipation (four studies) ${ }^{27457071}$ sensitivity ranged from 0.00 to 0.51 and specificity from 0.53 to 0.90 .

For peri-anal symptoms (five studies) the diagnostic performance depended on the definition used (table 7). When anal itch or anal protrusion was studied, ${ }^{40}$ sensitivity was significantly lower $(0.06)$ than when a more general definition such as peri-anal symptoms was used (0.36 to 0.56). ${ }^{8359}$ Patients with peri-anal symptoms might have a lower risk of colorectal cancer than patients without such symptoms, although the opposite might be true for the presence of peri-anal eczema. $^{34}$

Of the remaining symptoms (table 8 ) the presence of "mucus mixed with blood" might be informative as the risk of colorectal cancer was 14\% for those reporting this symptom compared with $3 \%$ for those without, but only one study investigated it. ${ }^{8}$

\section{Diagnostic performance of symptom combinations}

Five primary care, ${ }^{333444963}$ three primary-secondary interface, ${ }^{286568}$ and four secondary care studies $^{8284159606568}$ presented diagnostic data on a whole range of symptom combinations, including two classification systems that were originally developed to differentiate organic from non-organic disease 


\section{Table 9 | Diagnostic performance of symptom combinations and referral guidelines in diagnosis of colorectal cancer}

\begin{tabular}{|c|c|c|c|c|c|c|c|c|}
\hline Index test and setting & TP & FP & FN & TN & Sensitivity $(95 \% \mathrm{Cl})$ & Specificity $(95 \% \mathrm{Cl})$ & $\begin{array}{l}\text { Risk with positive test } \\
\text { result }(95 \% \mathrm{Cl})\end{array}$ & $\begin{array}{l}\text { Risk with negative test } \\
\text { result }(95 \% \mathrm{Cl})\end{array}$ \\
\hline \multicolumn{9}{|l|}{ Symptom combinations } \\
\hline \multicolumn{9}{|c|}{ All bleeding, $\mathrm{CIBH}$, abdominal pain, primary care } \\
\hline Ellis 2005 & 6 & 61 & 5 & 194 & $0.55(0.23$ to 0.83$)$ & $0.76(0.70$ to 0.81$)$ & 0.09 (0.03 to 0.19) & $0.03(0.01$ to 0.06$)$ \\
\hline \multicolumn{9}{|c|}{ All bleeding, prediction model including age, $\mathrm{CIBH}$, blood mixed with or on stool, primary care } \\
\hline Fijten 1995 & 9 & 26 & 0 & 234 & $1.00(0.66$ to 1.00$)$ & 0.90 (0.86 to 0.93$)$ & $0.26(0.13$ to 0.43$)$ & $0.00(0.00$ to 0.03$)$ \\
\hline \multicolumn{9}{|c|}{ All bleeding, $\mathrm{CIBH}$, age $>69$, primary care } \\
\hline Norrelund 1996 & 19 & 27 & 31 & 271 & $0.38(0.25$ to 0.53$)$ & $0.91(0.87$ to 0.94$)$ & $0.41(0.27$ to 0.57$)$ & $0.10(0.07$ to 0.14$)$ \\
\hline \multicolumn{9}{|c|}{ All bleeding, dark and mixed with stool, primary care } \\
\hline Robertson 2006 & 9 & 79 & 13 & 503 & $0.41(0.21$ to 0.64$)$ & $0.86(0.83$ to 0.89$)$ & $0.10(0.05$ to 0.19$)$ & $0.03(0.01$ to 0.04$)$ \\
\hline \multicolumn{9}{|l|}{ Bleeding, $\mathrm{CIBH}^{\star}$} \\
\hline Chohan 2005 & 29 & 123 & 35 & 275 & $0.45(0.33$ to 0.58$)$ & $0.69(0.64$ to 0.74$)$ & $0.19(0.13$ to 0.26$)$ & 0.11 (0.08 to 0.15$)$ \\
\hline \multicolumn{9}{|c|}{ Bleeding, $\mathrm{CIBH},>6$ weeks to looser/more frequent* } \\
\hline Flashman 2004, GP findings & 28 & 174 & 37 & 456 & $0.43(0.31$ to 0.56$)$ & $0.72(0.69$ to 0.76$)$ & 0.14 (0.09 to 0.19$)$ & $0.08(0.05$ to 0.10$)$ \\
\hline Flashman 2004, clinic findings & 26 & 144 & 39 & 486 & $0.40(0.28$ to 0.53$)$ & $0.77(0.74$ to 0.80$)$ & $0.15(0.10$ to 0.22$)$ & $0.07(0.05$ to 0.10$)$ \\
\hline \multicolumn{9}{|l|}{ Bleeding, CIBH $>6$ weeks, age $>45^{\star}$} \\
\hline Barwick 2004 & 3 & 45 & 11 & 85 & $0.21(0.05$ to 0.51$)$ & $0.65(0.57$ to 0.74$)$ & $0.06(0.01$ to 0.17$)$ & $0.12(0.06$ to 0.20$)$ \\
\hline \multicolumn{9}{|c|}{ Bleeding, no peri-anal symptoms, age $>60^{\star}$} \\
\hline Flashman 2004-GP findings & 17 & 143 & 48 & 487 & $0.26(0.16$ to 0.39$)$ & $0.96(0.92$ to 0.99$)$ & $0.13(0.08$ to 0.18$)$ & $0.09(0.07$ to 0.12$)$ \\
\hline Flashman 2004-clinic findings & 4 & 27 & 61 & 603 & $0.06(0.02$ to 0.15$)$ & $0.96(0.94$ to 0.97$)$ & 0.13 (0.04 to 0.30$)$ & 0.09 (0.07 to 0.12$)$ \\
\hline \multicolumn{9}{|c|}{ Bleeding, no peri-anal symptoms, age $>55^{\star}$} \\
\hline Chohan 2005 & 37 & 164 & 27 & 234 & $0.58(0.45$ to 0.70$)$ & $0.59(0.54$ to 0.64$)$ & $0.18(0.13$ to 0.25$)$ & $0.10(0.07$ to 0.15$)$ \\
\hline \multicolumn{9}{|c|}{ Bleeding, no peri-anal symptoms, age $>65^{\star}$} \\
\hline Barwick 2004 & 3 & 25 & 11 & 105 & $0.21(0.05$ to 0.51$)$ & $0.81(0.73$ to 0.87$)$ & $0.11(0.02$ to 0.28$)$ & $0.10(0.05$ to 0.16$)$ \\
\hline \multicolumn{9}{|c|}{$\mathrm{CIBH}>6$ weeks to looser/more frequent* } \\
\hline Chohan 2005 & 27 & 171 & 37 & 227 & $0.42(0.30$ to 0.55$)$ & $0.57(0.52$ to 0.62$)$ & 0.14 (0.09 to 0.19$)$ & 0.14 (0.10 to 0.19$)$ \\
\hline \multicolumn{9}{|c|}{$\mathrm{CIBH}>6$ weeks to looser/more frequent, age $>45^{\star}$} \\
\hline Barwick 2004 & 5 & 65 & 9 & 65 & $0.36(0.13$ to 0.65$)$ & $0.50(0.41$ to 0.59$)$ & $0.07(0.02$ to 0.16$)$ & 0.12 (0.06 to 0.22$)$ \\
\hline \multicolumn{9}{|l|}{$\mathrm{CIBH}>6$ weeks, no bleeding, age $>60^{*}$} \\
\hline Flashman 2004 - GP findings & 17 & 261 & 48 & 369 & $0.26(0.16$ to 0.39$)$ & $0.59(0.55$ to 0.62$)$ & $0.06(0.04$ to 0.10$)$ & $0.12(0.09$ to 0.15$)$ \\
\hline Flashman 2004 - clinic findings & 11 & 161 & 54 & 469 & 0.17 (0.09 to 0.28$)$ & $0.74(0.71$ to 0.78$)$ & $0.06(0.03$ to 0.11$)$ & $0.10(0.08$ to 0.13$)$ \\
\hline \multicolumn{9}{|l|}{ All bleeding, at least 1 of: dark re } \\
\hline Marderstein 2008 & 19 & 503 & 7 & 696 & $0.73(0.88$ to 0.52$)$ & $0.58(0.61$ to 0.55$)$ & $0.04(0.02$ to 0.06$)$ & 0.01 (0.00 to 0.02$)$ \\
\hline \multicolumn{9}{|l|}{ Bleeding, CIBH, secondary care } \\
\hline Thompson 2007 & 249 & 1802 & 218 & 6260 & $0.53(0.49$ to 0.58$)$ & $0.78(0.77$ to 0.79$)$ & $0.12(0.11$ to 0.14$)$ & $0.03(0.03$ to 0.04$)$ \\
\hline Thompson 2008 & 466 & 4096 & 480 & 11391 & $0.49(0.46$ to 0.53$)$ & $0.74(0.73$ to 0.74$)$ & $0.10(0.09$ to 0.11$)$ & $0.04(0.04$ to 0.04$)$ \\
\hline \multicolumn{9}{|c|}{ Bleeding, CIBH, peri-anal symptoms, secondary care } \\
\hline Thompson 2007 & 101 & 1200 & 366 & 6862 & $0.22(0.18$ to 0.26$)$ & $0.85(0.84$ to 0.86$)$ & 0.08 (0.06 to 0.09$)$ & $0.05(0.05$ to 0.06$)$ \\
\hline Bleeding, $\mathrm{CIBH}$, no peri-anal symp & $\mathrm{ms}, \mathrm{s}$ & ondary & & & & & & \\
\hline Thompson 2007 & 148 & 602 & 319 & 7460 & $0.32(0.28$ to 0.36$)$ & $0.93(0.92$ to 0.93$)$ & $0.20(0.17$ to 0.23$)$ & $0.04(0.04$ to 0.05$)$ \\
\hline Bleeding, $\mathrm{CIBH}$, abdominal pain, $\mathrm{s}$ & conda & care & & & & & & \\
\hline Thompson 2007 & 101 & 1068 & 366 & 6994 & $0.22(0.18$ to 0.26$)$ & 0.87 (0.86 to 0.88$)$ & $0.09(0.07$ to 0.10$)$ & $0.05(0.05$ to 0.06$)$ \\
\hline Bleeding, $\mathrm{CIBH}$, abdominal pain, $\mathrm{s}$ & conda & care & & & & & & \\
\hline Thompson 2008 & 181 & 2696 & 765 & 12791 & $0.19(0.17$ to 0.22$)$ & $0.83(0.82$ to 0.83$)$ & $0.06(0.05$ to 0.07$)$ & $0.06(0.05$ to 0.06$)$ \\
\hline Bleeding, $\mathrm{ClBH}$, no abdominal pai & secol & ary care & & & & & & \\
\hline Thompson 2007 & 148 & 734 & 319 & 7328 & $0.32(0.28$ to 0.36$)$ & 0.91 (0.90 to 0.92$)$ & $0.17(0.14$ to 0.19$)$ & $0.04(0.04$ to 0.05$)$ \\
\hline Bleeding, no $\mathrm{CIBH}$, secondary care & & & & & & & & \\
\hline Thompson 2007 & 84 & 3277 & 383 & 4785 & $0.18(0.15$ to 0.22$)$ & $0.59(0.58$ to 0.60$)$ & $0.03(0.02$ to 0.03$)$ & 0.07 (0.07 to 0.08$)$ \\
\hline Bleeding, no $\mathrm{CIBH}$, peri-anal symp & $\mathrm{ms}, \mathrm{s}$ & ondary & & & & & & \\
\hline Thompson 2007 & 37 & 2515 & 430 & 5547 & 0.08 (0.06 to 0.11$)$ & $0.69(0.68$ to 0.70$)$ & 0.01 (0.01 to 0.02$)$ & 0.07 (0.07 to 0.08$)$ \\
\hline Bleeding, no $\mathrm{CIBH}$, no peri-anal sy & ptom & econd & care & & & & & \\
\hline Thompson 2007 & 47 & 762 & 420 & 7300 & $0.10(0.08$ to 0.13$)$ & $0.91(0.90$ to 0.91$)$ & $0.06(0.04$ to 0.08$)$ & $0.05(0.05$ to 0.06$)$ \\
\hline Bleeding, abdominal pain, seconc & ry car & & & & & & & \\
\hline Thompson 2008 & 227 & 4140 & 719 & 11347 & $0.24(0.21$ to 0.27$)$ & $0.73(0.73$ to 0.74$)$ & 0.05 (0.05 to 0.06$)$ & $0.06(0.06$ to 0.06$)$ \\
\hline Bleeding, peri-anal symptoms, sec & ndary & & & & & & & \\
\hline Thompson 2007 & 138 & 3715 & 329 & 4347 & $0.30(0.25$ to 0.34$)$ & $0.54(0.53$ to 0.55$)$ & $0.04(0.03$ to 0.04$)$ & $0.07(0.06$ to 0.08$)$ \\
\hline
\end{tabular}




\begin{tabular}{|c|c|c|c|c|c|c|c|c|}
\hline Index test and setting & TP & FP & FN & TN & Sensitivity $(95 \% \mathrm{Cl})$ & Specificity $(95 \% \mathrm{Cl})$ & $\begin{array}{l}\text { Risk with positive test } \\
\text { result }(95 \% \mathrm{Cl})\end{array}$ & $\begin{array}{l}\text { Risk with negative test } \\
\text { result }(95 \% \mathrm{Cl})\end{array}$ \\
\hline \multicolumn{9}{|c|}{ Bleeding, no peri-anal symptoms, secondary care } \\
\hline Thompson 2007 & 195 & 1364 & 272 & 6698 & $0.42(0.37$ to 0.46$)$ & $0.83(0.82$ to 0.84$)$ & $0.13(0.11$ to 0.14$)$ & 0.04 (0.04 to 0.04$)$ \\
\hline \multicolumn{9}{|c|}{$\mathrm{CIBH}$, no bleeding, secondary care } \\
\hline Thompson 2007 & 110 & 1725 & 357 & 6337 & $0.24(0.20$ to 0.28$)$ & $0.79(0.78$ to 0.80$)$ & $0.06(0.05$ to 0.07$)$ & 0.05 (0.05 to 0.06$)$ \\
\hline \multicolumn{9}{|c|}{$\mathrm{CIBH}$, no bleeding, abdominal pain, secondary care } \\
\hline Thompson 2007 & 40 & 726 & 427 & 7336 & 0.09 (0.06 to 0.12$)$ & 0.91 (0.90 to 0.92$)$ & 0.05 (0.04 to 0.07$)$ & $0.06(0.05$ to 0.06$)$ \\
\hline \multicolumn{9}{|c|}{ Abdominal pain, $\mathrm{CIBH}$, secondary care } \\
\hline Thompson 2008 & 246 & 4525 & 700 & 10962 & $0.26(0.23$ to 0.29$)$ & $0.71(0.70$ to 0.72$)$ & $0.05(0.05$ to 0.06$)$ & $0.06(0.06$ to 0.06$)$ \\
\hline \multicolumn{9}{|c|}{ Abdominal pain, no $\mathrm{CIBH}$, no bleeding, secondary care } \\
\hline Thompson 2007 & 16 & 634 & 451 & 7428 & $0.03(0.02$ to 0.06$)$ & $0.92(0.92$ to 0.93$)$ & $0.03(0.01$ to 0.04$)$ & $0.06(0.05$ to 0.06$)$ \\
\hline \multicolumn{9}{|c|}{ Selva score, secondary care, Selvachandran $2002 \dagger$} \\
\hline$\geq 40 v<40$ & 151 & 1733 & 5 & 1413 & 0.97 (0.93 to 0.99$)$ & $0.45(0.43$ to 0.47$)$ & $0.08(0.07$ to 0.09$)$ & $0.00(0.00$ to 0.01$)$ \\
\hline$\geq 50 v<50$ & 134 & 1167 & 22 & 1979 & $0.86(0.79$ to 0.91$)$ & $0.63(0.61$ to 0.65$)$ & $0.10(0.09$ to 0.12$)$ & 0.01 (0.01 to 0.02$)$ \\
\hline$\geq 60 v<60$ & 72 & 495 & 23 & 1678 & $0.76(0.66$ to 0.84$)$ & $0.77(0.75$ to 0.79$)$ & $0.13(0.10$ to 0.16$)$ & 0.01 (0.01 to 0.02$)$ \\
\hline$\geq 70 v<70$ & 66 & 266 & 29 & 1907 & $0.70(0.59$ to 0.79$)$ & 0.88 (0.86 to 0.89$)$ & $0.20(0.16$ to 0.25$)$ & 0.02 (0.01 to 0.02$)$ \\
\hline \multicolumn{9}{|l|}{ Bellentani >0, primary care } \\
\hline Bellentani 1990 & 10 & 111 & 0 & 133 & $1.00(0.69$ to 1.00$)$ & $0.55(0.48$ to 0.61$)$ & $0.08(0.04$ to 0.15$)$ & $0.00(0.00$ to 0.03$)$ \\
\hline \multicolumn{9}{|l|}{ Kruis $\ll 44$, primary care } \\
\hline Bellentani 1990 & 9 & 84 & 1 & 160 & $0.90(0.56$ to 1.00$)$ & $0.66(0.59$ to 0.72$)$ & $0.10(0.05$ to 0.18$)$ & 0.01 (0.00 to 0.03$)$ \\
\hline \multicolumn{9}{|l|}{ Guidelines fulfilled } \\
\hline \multicolumn{9}{|c|}{ Two week referral guideline, two week referral clinic } \\
\hline Chohan 2005 & 59 & 278 & 5 & 120 & $0.92(0.83$ to 0.97$)$ & $0.30(0.26$ to 0.35$)$ & $0.18(0.14$ to 0.22$)$ & 0.04 (0.01 to 0.09$)$ \\
\hline Debnath 2002 & 18 & 129 & 3 & 87 & $0.86(0.64$ to 0.97$)$ & $0.40(0.34$ to 0.47$)$ & $0.12(0.07$ to 0.19$)$ & 0.03 (0.01 to 0.09 ) \\
\hline Eccersley 2003 & 24 & 71 & 2 & 83 & $0.92(0.75$ to 0.99$)$ & $0.54(0.46$ to 0.62$)$ & $0.25(0.17$ to 0.35$)$ & 0.02 (0.00 to 0.08$)$ \\
\hline Flashman 2004 & 58 & 363 & 7 & 267 & $0.89(0.79$ to 0.96$)$ & $0.42(0.39$ to 0.46$)$ & 0.14 (0.11 to 0.17$)$ & 0.03 (0.01 to 0.05$)$ \\
\hline \multicolumn{9}{|c|}{ Two week referral guideline, secondary care } \\
\hline Mahon 2002 & 17 & 102 & 1 & 127 & $0.94(0.73$ to 1.00$)$ & $0.56(0.49$ to 0.62$)$ & 0.14 (0.09 to 0.22$)$ & 0.01 (0.00 to 0.04$)$ \\
\hline \multicolumn{9}{|c|}{ Adjusted two week referral guideline (only 3 criteria) secondary care } \\
\hline Selvachandran $2002 \dagger$ & 125 & 1444 & 31 & 1702 & $0.80(0.73$ to 0.86$)$ & $0.54(0.52$ to 0.56$)$ & $0.08(0.07$ to 0.09$)$ & $0.02(0.01$ to 0.03$)$ \\
\hline
\end{tabular}

$\mathrm{TP}=$ true positives; $\mathrm{FP}=$ false positives; $\mathrm{FN}=$ false negatives; $\mathrm{TN}=$ true negatives; $\mathrm{CIBH}=$ change in bowel habit; $\mathrm{FOBT}=$ faecal occult blood test.

*Two week referral criterion.

†For this study we extracted data for some index tests from a more recent paper of Hodder et al. ${ }^{72}$

(Bellentani and Kruis criteria ${ }^{63}$ ), a self developed prediction rule by Fijten et al, ${ }^{34}$ and an experience based scoring method to predict colorectal cancer (Selva score $^{8}$ ) (table 9). The three primary-secondary interface studies presented diagnostic data on individual referral criteria of the two week referral guideline.

Sensitivity ranged from 0.03 for a combination of abdominal pain without rectal bleeding or change in bowel habit, ${ }^{59}$ to a sensitivity of 1.00 for a prediction

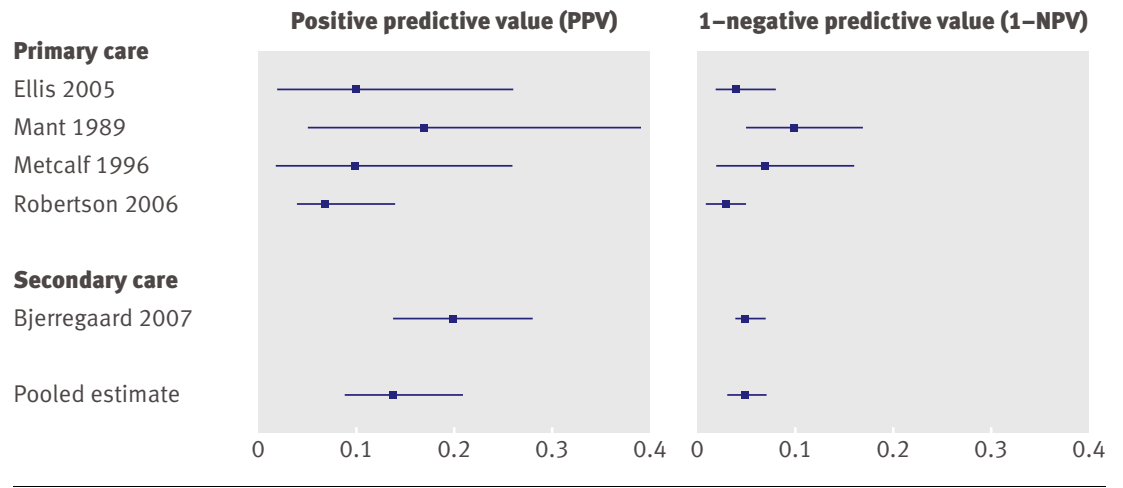

Fig $4 \mid$ Risk of colorectal cancer in patients with rectal bleeding/dark blood (positive predictive value) versus risk in those without rectal bleeding/dark blood (1-negative predictive value) rule including age, change in bowel habit, and blood mixed with or on stool. ${ }^{34}$ Specificity ranged from 0.50 for a combination of change in bowel habit and age $\geq 45^{28}$ to a specificity of 0.96 for a combination of rectal bleeding, (absence of) peri-anal symptoms, and age $\geq 60 .{ }^{68} \mathrm{~A}$ prediction rule showed favourable results for both sensitivity $(1.00)$ and specificity $(0.90) .^{34}$

Thompson et al found that the risk of colorectal cancer increased from $6 \%$ to $12 \%$ when rectal bleeding is accompanied by a change in bowel habit. ${ }^{59}$ When additional information was gathered on peri-anal symptoms and they are absent, the risk increased further to $20 \%$. When rectal bleeding was accompanied by perianal symptoms but not by a change in bowel habit, the risk of colorectal cancer decreased from $6 \%$ to $1 \% .^{59}$

Four studies evaluated the two week referral guideline in a two week referral clinic and two studies in secondary care (see appendix A for a description of the guideline). The formulation of the two week referral criteria differed (slightly) across studies. Selvachandran et al included only three of the six criteria. ${ }^{8}$ Sensitivity ranged from 0.80 for the abridged version ${ }^{8}$ to $0.94^{69}$; specificity ranged from $0.30^{65}$ to $0.56 .^{69}$ For those meeting the guideline (that is, positive score on at 
least one of the six criteria) the risk varied from $8 \%{ }^{8}$ to $25 \%{ }^{67}$ with a median of $14 \%$, while for patients who did not meet the guideline the risk varied from $1 \%{ }^{69}$ to $4 \% 0^{65}$ with a median of $3 \%$ (table 2 , fig 6 ).

\section{Diagnostic performance of blood tests}

Eight studies reported on the diagnostic value of iron deficiency anaemia, ${ }^{2729454655656871}$ and one primary care study $^{34}$ on the diagnostic value of haemoglobin, erythrocyte sedimentation rate, and white cell count (table 10). For (iron deficiency) anaemia sensitivity varies widely from 0.07 to 0.68 , while specificity ranges from 0.83 to 0.95 . In three of the eight studies the risk for colorectal cancer was significantly higher among those with a positive test result than among those with a negative test result (table 2 , fig 7 ). ${ }^{274565}$

\section{Diagnostic performance of faecal occult blood test}

Table 11 gives details of the 15 studies that reported on the diagnostic performance of guaiac based faecal occult blood tests, ${ }^{11} 123134-384347485356-58$ three studies on do-it-yourself tests, ${ }^{48567}$ eight studies on immunochemical based faecal occult blood tests, ${ }^{36} 39424750-5358$ and one study on a combination of the occult blood tests. ${ }^{47}$ Few studies reported detailed information on diet restrictions before the test.

For guaiac based tests sensitivity ranged from 0.33 for the Coloscreen self test ${ }^{48}$ to 1.00 for a Haemoccult test, ${ }^{12}$ while specificity ranged from 0.72 for a Fecatwin test $^{57}$ to 0.94 for the Coloscreen self test. ${ }^{48}$ Sensitivity of the self tests was low (range 0.33-0.57). For immunochemical based faecal occult blood tests sensitivity ranged from 0.70 for an iFOBT strip device ${ }^{50}$ to 1.00 for HemeSelect, Hemoblot, Insure, and faecal haemoglobin. ${ }^{363953}$ Specificity ranged from 0.71 for a

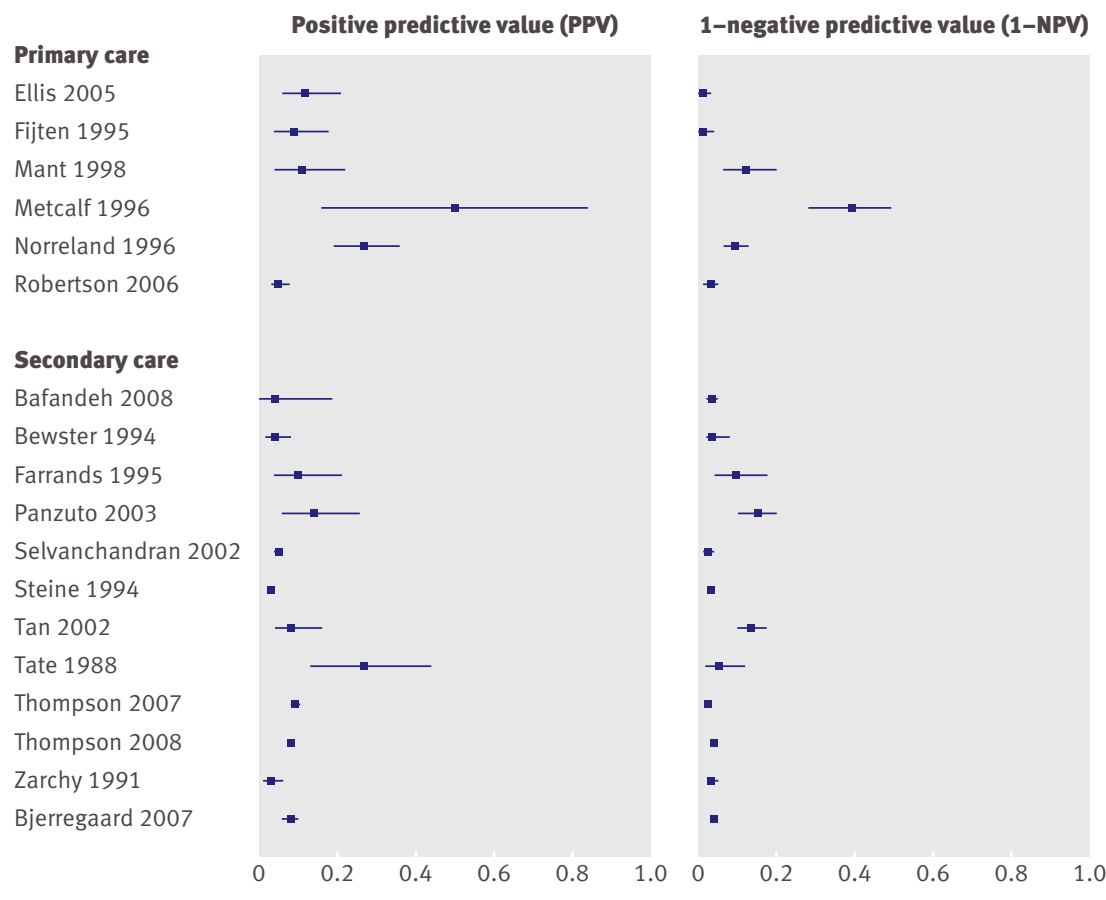

Fig $\mathbf{5}$ | Risk of colorectal cancer in patients reporting change in bowel habit (positive predictive value) versus risk in patients not reporting this symptom (1-negative predictive value) haemoglobin-albumin complex ${ }^{51}$ to 0.93 for an iFOBT strip device. $^{50}$

The risk for colorectal cancer was significantly higher among patients with a positive test result than among those with a negative test result, with the exception of the study of Fijten et al ${ }^{34}$ (table 11) that included solely patients with rectal bleeding. For guaiac based tests the median risk was 0.28 among those with a positive test result and 0.01 for those with a negative test result, while these numbers were 0.21 and 0.00 , respectively for immunochemical based tests (table 2, figs 8 and 9).

\section{Preplanned subgroup analyses}

Because of lack of data in one or both subgroups several preplanned subgroup analyses could not be carried out. Table 12 presents the results of the subgroup analyses between studies for which sufficient data were available. Comparing the subgroups' (ranges of) values of sensitivity and specificity shows that none of the factors was clearly able to explain the tests' heterogeneous results.

We looked at several subgroup analyses within studies. Sensitivity of the immunochemical based faecal occult blood tests was better than that of the guaiac based tests, ${ }^{365358}$ and better for the regular guaiac based tests than the self tests (table 13). ${ }^{485657}$ These findings are confirmed by the between study findings (table 2). Subgroup analyses within studies on Dukes's types stages showed that immunochemical based tests were better than guaiac based tests in detecting Dukes's A and B, ${ }^{5358}$ and sensitivity seemed to be higher at all locations. ${ }^{58}$ This, however, was based on one or two studies with a small number of cases (table 14).

\section{DISCUSSION}

The performance of tests in diagnosing colorectal cancer in adult patients with symptoms varied widely. Sensitivity was consistently high for age $\geq 50$ (range 0.81 0.96 , median 0.91) and for the two week referral guideline (range 0.80-0.94, median 0.92), but these lacked specificity (medians 0.36 and 0.42 , respectively). These tests are suitable to rule out colorectal cancer at the cost of a high number of patients needing further diagnostic testing. Specificity was consistently high for family history (range 0.75-0.98, median 0.91), weight loss (range 0.72-0.96, median 0.89), and iron deficiency anaemia $(0.83-0.95$, median 0.92$)$, but all tests lacked sensitivity (medians $0.16,0.20$ and 0.13 , respectively). These tests are suitable to rule in colorectal cancer but at the cost of missing a considerable proportion of cases. Only the immunochemical based faecal occult blood tests had both a reasonable sensitivity (range $0.70-1.00$, median 0.95) and specificity (range 0.710.93 , median 0.84 ).

\section{Diagnostic tests for colorectal cancer in primary care}

This review focuses on the diagnostic performance of tests for patients who present with non-acute lower abdominal symptoms in primary care. We found that 
Table 10 |Diagnostic performance of blood tests in diagnosis of colorectal cancer

\begin{tabular}{|c|c|c|c|c|c|c|c|c|}
\hline Index test and setting & TP & FP & FN & TN & $\begin{array}{l}\text { Sensitivity } \\
(95 \% \mathrm{Cl})\end{array}$ & $\begin{array}{l}\text { Specificity } \\
(95 \% \mathrm{Cl})\end{array}$ & $\begin{array}{l}\text { Risk with positive test } \\
\text { result }(95 \% \mathrm{Cl})\end{array}$ & $\begin{array}{l}\text { Risk with negative test } \\
\text { result }(95 \% \mathrm{Cl})\end{array}$ \\
\hline \multicolumn{9}{|c|}{ Iron deficiency anaemia (haemoglobin $<6.2 \mathrm{mmol} / \mathrm{l}$ in men and postmenopausal women), two week referral clinic } \\
\hline Chohan 2005 & 13 & 25 & 51 & 373 & $0.20(0.11$ to 0.32$)$ & $0.94(0.91$ to 0.96$)$ & $0.34(0.20$ to 0.51$)$ & $0.12(0.09$ to 0.16$)$ \\
\hline \multicolumn{9}{|c|}{ Iron deficiency anaemia (haemoglobin $\leq 6.2 \mathrm{mmol} / \mathrm{l}$ in women aged $>50, \leq 6.8 \mathrm{mmol} / \mathrm{l}$ in men), two week referral clinic } \\
\hline Flashman 2004, GP findings & 6 & 49 & 59 & 581 & $0.09(0.04$ to 0.19$)$ & $0.92(0.90$ to 0.94$)$ & $0.11(0.04$ to 0.22$)$ & 0.09 (0.07 to 0.12$)$ \\
\hline Flashman 2004 , clinic findings & 6 & 47 & 59 & 583 & 0.09 (0.04 to 0.19$)$ & $0.93(0.90$ to 0.95$)$ & $0.11(0.04$ to 0.23$)$ & $0.09(0.07$ to 0.12$)$ \\
\hline \multicolumn{9}{|c|}{ Unexplained anaemia, present $v$ absent, secondary care } \\
\hline Badandeh 2008 & 5 & 30 & 11 & 434 & 0.31 (0.11 to 0.59$)$ & $0.94(0.91$ to 0.96$)$ & $0.14(0.05$ to 0.30$)$ & $0.03(0.01$ to 0.04$)$ \\
\hline \multicolumn{9}{|l|}{ Anaemia, secondary care } \\
\hline Bjerregaard 2007 & 14 & 197 & 108 & 1853 & 0.12 (0.06 to 0.19$)$ & $0.90(0.89$ to 0.92$)$ & 0.07 (0.04 to 0.11$)$ & $0.06(0.05$ to 0.07$)$ \\
\hline \multicolumn{9}{|c|}{ Iron deficiency anaemia (haemoglobin $<8.7 \mathrm{mmol} / \mathrm{l}$ in men, $<7.5 \mathrm{mmol} / \mathrm{l}$ in women; ferritin $<6.7 \mathrm{pmol} / \mathrm{l}$ ), secondary care } \\
\hline Panzuto 2003 & 28 & 41 & 13 & 198 & $0.68(0.52$ to 0.82$)$ & $0.83(0.78$ to 0.87$)$ & $0.41(0.29$ to 0.53$)$ & $0.06(0.03$ to 0.10$)$ \\
\hline \multicolumn{9}{|c|}{ Iron deficiency anaemia present $v$ absent, secondary care } \\
\hline Tan 2002 & 8 & 35 & 50 & 392 & $0.14(0.06$ to 0.25$)$ & $0.92(0.89$ to 0.94$)$ & $0.19(0.08$ to 0.33$)$ & $0.11(0.09$ to 0.15$)$ \\
\hline \multicolumn{9}{|c|}{ (Iron deficiency) anaemia, secondary care } \\
\hline Tate 1988 & 1 & 10 & 13 & 106 & $0.07(0.00$ to 0.34$)$ & $0.91(0.85$ to 0.96$)$ & $0.09(0.00$ to 0.41$)$ & 0.11 (0.06 to 0.18$)$ \\
\hline \multicolumn{9}{|c|}{ All constipated, anaemia, secondary care } \\
\hline Pepin 2002 & 1 & 27 & 7 & 528 & $0.13(0.00$ to 0.53$)$ & 0.95 (0.93 to 0.97$)$ & 0.04 (0.00 to 0.18$)$ & 0.01 (0.01 to 0.03$)$ \\
\hline \multicolumn{9}{|c|}{ All bleeding, haemoglobin $<8.5 \mathrm{mmol} / \mathrm{l}$ in men, $<7.5 \mathrm{mmol} / \mathrm{l}$ in women, primary care } \\
\hline Fijten 1995 & 2 & 12 & 3 & 208 & $0.40(0.05$ to 0.85$)$ & 0.95 (0.91 to 0.97$)$ & $0.14(0.02$ to 0.43$)$ & $0.01(0.00$ to 0.04$)$ \\
\hline \multicolumn{9}{|c|}{ All bleeding, erythrocyte sedimentation rate $>30 \mathrm{~mm}$ in first hour, primary care } \\
\hline Fijten 1995 & 2 & 10 & 3 & 210 & $0.40(0.05$ to 0.85$)$ & $0.96(0.92$ to 0.98$)$ & $0.17(0.02$ to 0.48$)$ & $0.01(0.00$ to 0.04$)$ \\
\hline \multicolumn{9}{|c|}{ All bleeding, white cell count $>10^{9} / \mathrm{l}$, primary care } \\
\hline Fijten 1995 & 3 & 22 & 2 & 192 & $0.60(0.15$ to 0.95$)$ & $0.90(0.85$ to 0.93$)$ & $0.12(0.03$ to 0.31$)$ & $0.01(0.00$ to 0.04$)$ \\
\hline
\end{tabular}

$\mathrm{TP}=$ true positives; $\mathrm{FP}=$ false positives; $\mathrm{FN}=$ false negatives; $\mathrm{TN}=$ true negatives.

only a few studies were clearly carried out in primary care populations. We excluded screening studies, which would also include a large proportion of people without symptoms. Screening is useful if early stages of colorectal cancer can be detected, which have a favourable prognosis. In primary care, all colorectal cancer should be diagnosed, and preferably at an early stage. Therefore, it is useful to make a distinction between early stages (Dukes's A/B) - that is, resectable colorectal cancer-and later stages (Dukes's C/D). Some of the tests reflect symptoms of later stages, such as weight loss and iron deficiency anaemia, and will therefore not help to identify early stages of colorectal cancer.

When a patient presents to primary care with abdominal symptoms several differential diagnoses can be considered (such as colorectal cancer, irritable bowel syndrome, coeliac disease) and general practitioners should identify patients who should be referred

\section{Positive predictive value (PPV)}

Chohan 2005 Debnath 2002 Eccersley 2003 Flashman 2004 Mahon 2002

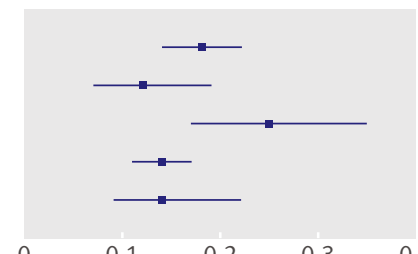

0 1-negative predictive value (1-NPV)

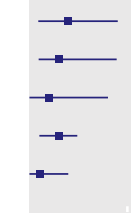

0.1 for further diagnosis. Our review focused on colorectal cancer, yet to the clinician a positive test result (such as diarrhoea) leading to a diagnosis of inflammatory disease might be considered a true positive result.

Primary care settings differ between countries, and in only a few countries do general practitioners act as a gatekeeper to specialist clinical care. In other countries specialist care may be directly accessible. Therefore we also included two week referral clinics and secondary care populations with a low prevalence of colorectal cancer, which might reflect populations with a similar spectrum of disease as in primary care and a limited risk of investigation bias. Many studies, both in primary and secondary care settings, however, enrolled a selective population of patients by using the presence of a specific complaint as an inclusion criterion. For example, seven primary care studies investigating the diagnostic performance of signs and symptoms used rectal bleeding as an inclusion criterion. We presented the findings in such a way that differences between settings and populations can be easily identified.

\section{Diagnostic performance}

Symptoms and signs

Of the typical symptoms of colorectal cancer, only weight loss had some diagnostic value with a fairly high specificity. This seemed to be translated in clear differences between the probability of colorectal cancer among patients with or without apparent weight loss (positive predictive value $v 1$-negative predictive
Fig $6 \mid$ Risk of colorectal cancer in patients meeting two week referral rule (positive predictive value) versus risk in those not meeting two week referral (1-negative predictive value) 


\section{Table 11|Diagnostic performance of faecal occult blood tests in diagnosis of colorectal cancer}

\begin{tabular}{|c|c|c|c|c|c|c|c|c|}
\hline Index test and setting & TP & FP & FN & TN & Sensitivity $(95 \% \mathrm{Cl})$ & Specificity $(95 \% \mathrm{Cl})$ & $\begin{array}{l}\text { Risk with positive test } \\
\text { result }(95 \% \mathrm{Cl})\end{array}$ & $\begin{array}{l}\text { Risk with negative test } \\
\text { result }(95 \% \mathrm{Cl})\end{array}$ \\
\hline \multicolumn{9}{|c|}{ Positive $v$ negative result on guaiac based faecal occult blood test } \\
\hline \multicolumn{9}{|c|}{ Haemoccult II, diet, primary care } \\
\hline Castiglione 1987 & 17 & 79 & 13 & 746 & $0.57(0.37$ to 0.75$)$ & $0.90(0.88$ to 0.92$)$ & $0.18(0.11$ to 0.27$)$ & $0.02(0.01$ to 0.03$)$ \\
\hline \multicolumn{9}{|c|}{ All bleeding, Haemoccult, diet, primary care } \\
\hline Fijten 1995 & 2 & 39 & 3 & 181 & $0.40(0.05$ to 0.85$)$ & $0.82(0.77$ to 0.87$)$ & $0.05(0.01$ to 0.17$)$ & $0.02(0.00$ to 0.05$)$ \\
\hline \multicolumn{9}{|c|}{ Fecatwin/Feca, no info on diet, secondary care } \\
\hline Pye 1989 & 18 & 109 & 6 & 402 & $0.75(0.53$ to 0.90$)$ & $0.79(0.75$ to 0.82$)$ & 0.14 (0.09 to 0.22$)$ & $0.02(0.01$ to 0.03$)$ \\
\hline \multicolumn{9}{|c|}{ Fecatwin, no info on diet secondary care } \\
\hline Tate 1990 & 14 & 91 & 1 & 229 & $0.93(0.68$ to 1.00$)$ & $0.72(0.66$ to 0.76$)$ & $0.13(0.08$ to 0.21$)$ & $0.00(0.00$ to 0.02$)$ \\
\hline \multicolumn{9}{|c|}{ Haemoccult, diet, secondary care } \\
\hline Goulston 1980 & 8 & 16 & 2 & 72 & $0.80(0.44$ to 0.98$)$ & $0.82(0.72$ to 0.89$)$ & $0.33(0.16$ to 0.55$)$ & 0.03 (0.00 to 0.09$)$ \\
\hline Thomas 1992 & 29 & 20 & 21 & 262 & 0.58 (0.43 to 0.72$)$ & $0.93(0.89$ to 0.96$)$ & 0.59 (0.44 to 0.73$)$ & $0.07(0.05$ to 0.11$)$ \\
\hline \multicolumn{9}{|c|}{ Haemoccult, no diet, secondary care } \\
\hline Falkson 1993 & 19 & 32 & 4 & 403 & $0.83(0.61$ to 0.95$)$ & $0.93(0.90$ to 0.95$)$ & $0.37(0.24$ to 0.52$)$ & $0.01(0.00$ to 0.03$)$ \\
\hline Jeanson 1994 & 8 & 22 & 3 & 102 & $0.73(0.39$ to 0.94$)$ & $0.82(0.74$ to 0.89$)$ & $0.27(0.12$ to 0.46$)$ & $0.03(0.01$ to 0.08$)$ \\
\hline Kimmig 1989 & 22 & 139 & 2 & 371 & $0.92(0.73$ to 0.99$)$ & $0.73(0.69$ to 0.77$)$ & $0.14(0.09$ to 0.20$)$ & 0.01 (0.00 to 0.02$)$ \\
\hline Leicester 1983 & 28 & 108 & 9 & 597 & $0.76(0.59$ to 0.88$)$ & $0.85(0.82$ to 0.87$)$ & $0.21(0.14$ to 0.28$)$ & $0.02(0.01$ to 0.03$)$ \\
\hline \multicolumn{9}{|c|}{ Haemoccult, no info on diet, secondary care } \\
\hline Farrands 1985 & 13 & 21 & 0 & 105 & $1.00(0.75$ to 1.00$)$ & $0.83(0.76$ to 0.89$)$ & $0.38(0.22$ to 0.56$)$ & 0.00 (0.00 to 0.04$)$ \\
\hline Pye 1990 & 13 & 31 & 11 & 328 & $0.54(0.33$ to 0.74$)$ & $0.91(0.88$ to 0.94$)$ & $0.30(0.17$ to 0.45$)$ & $0.03(0.02$ to 0.06$)$ \\
\hline Tate 1989 & 12 & 30 & 3 & 230 & $0.80(0.52$ to 0.96$)$ & $0.89(0.84$ to 0.92$)$ & $0.29(0.16$ to 0.45$)$ & $0.01(0.00$ to 0.04$)$ \\
\hline Tate 1990 & 16 & 33 & 4 & 262 & $0.80(0.56$ to 0.94$)$ & $0.89(0.85$ to 0.92$)$ & $0.33(0.20$ to 0.48$)$ & $0.02(0.00$ to 0.04$)$ \\
\hline \multicolumn{9}{|c|}{ Haemoccult II, diet, secondary care } \\
\hline Niv 1995 & 9 & 114 & 4 & 312 & $0.69(0.39$ to 0.91$)$ & $0.73(0.69$ to 0.77$)$ & $0.07(0.03$ to 0.13$)$ & 0.01 (0.00 to 0.03$)$ \\
\hline \multicolumn{9}{|c|}{ Haemoccult II Sensa, diet, secondary care } \\
\hline Smith 2006 & 5 & 19 & 2 & 135 & $0.71(0.29$ to 0.96$)$ & $0.88(0.81$ to 0.92$)$ & $0.21(0.07$ to 0.42$)$ & $0.02(0.00$ to 0.05$)$ \\
\hline \multicolumn{9}{|c|}{ Self-Test Coloscreen, no info on diet, secondary care } \\
\hline Pye 1990 & 8 & 22 & 16 & 331 & $0.33(0.16$ to 0.55$)$ & $0.94(0.91$ to 0.96$)$ & $0.27(0.12$ to 0.46$)$ & $0.05(0.03$ to 0.07$)$ \\
\hline \multicolumn{9}{|c|}{ Self-Test E-Z Detect, no info on diet, secondary care } \\
\hline Tate 1989 & 8 & 41 & 14 & 341 & $0.36(0.17$ to 0.59$)$ & $0.89(0.86$ to 0.92$)$ & $0.16(0.07$ to 0.30$)$ & $0.04(0.02$ to 0.07$)$ \\
\hline Tate 1990 & 8 & 34 & 6 & 271 & $0.57(0.29$ to 0.82$)$ & $0.89(0.85$ to 0.92$)$ & $0.19(0.09$ to 0.34$)$ & $0.02(0.01$ to 0.05$)$ \\
\hline
\end{tabular}

Positive $v$ negative result on immunochemical based faecal occult blood test

HemeSelect, secondary care

\begin{tabular}{|c|c|c|c|c|c|c|c|c|}
\hline Jeanson 1994 & 11 & 24 & 0 & 100 & $1.00(0.72$ to 1.00$)$ & $0.81(0.73$ to 0.87$)$ & 0.31 (0.17 to 0.49$)$ & $0.00(0.00$ to 0.04$)$ \\
\hline Thomas 1992 & 47 & 62 & 3 & 220 & 0.94 (0.84 to 0.99$)$ & $0.78(0.73$ to 0.83$)$ & $0.43(0.34$ to 0.53$)$ & $0.01(0.00$ to 0.04$)$ \\
\hline \multicolumn{9}{|c|}{ Hemoblot, secondary care } \\
\hline Jeanson 1994 & 11 & 29 & 0 & 95 & $1.00(0.72$ to 1.00$)$ & $0.77(0.68$ to 0.84$)$ & $0.28(0.15$ to 0.44$)$ & $0.00(0.00$ to 0.04$)$ \\
\hline \multicolumn{9}{|c|}{ IFOBT strip device, secondary care } \\
\hline Shastri 2008 & 37 & 26 & 16 & 334 & 0.70 (0.56 to 0.82$)$ & $0.93(0.90$ to 0.95$)$ & 0.59 (0.46 to 0.71$)$ & $0.05(0.03$ to 0.07$)$ \\
\hline \multicolumn{9}{|c|}{ Immunohemostick, secondary care } \\
\hline Miyoshi 2000 & 11 & 140 & 3 & 1144 & $0.79(0.49$ to 0.95$)$ & $0.89(0.87$ to 0.91$)$ & 0.07 (0.04 to 0.13$)$ & $0.00(0.00$ to 0.01$)$ \\
\hline \multicolumn{9}{|c|}{ InSure, secondary care } \\
\hline Smith 2006 & 7 & 30 & 0 & 124 & $1.00(0.59$ to 1.00$)$ & $0.81(0.73$ to 0.87$)$ & $0.19(0.08$ to 0.35$)$ & $0.00(0.00$ to 0.03$)$ \\
\hline \multicolumn{9}{|c|}{ Faecal haemoglobin albumin $>2 \mu \mathrm{g} / \mathrm{g}$ faeces, secondary care } \\
\hline Sieg 1998 & 41 & 204 & 2 & 492 & 0.95 (0.84 to 0.99$)$ & $0.71(0.67$ to 0.74$)$ & $0.17(0.12$ to 0.22$)$ & $0.00(0.00$ to 0.02$)$ \\
\hline Sieg 1999 & 19 & 115 & 4 & 483 & $0.83(0.61$ to 0.95$)$ & $0.81(0.77$ to 0.84$)$ & 0.14 (0.09 to 0.21$)$ & $0.01(0.00$ to 0.02$)$ \\
\hline \multicolumn{9}{|c|}{ Faecal haemoglobin $>75 \mathrm{ng} / \mathrm{ml}$, secondary care } \\
\hline Levi 2007 & 6 & 61 & 0 & 404 & 1.00 (0.54 to 1.00$)$ & $0.87(0.84$ to 0.90$)$ & $0.09(0.03$ to 0.19$)$ & $0.00(0.00$ to 0.01$)$ \\
\hline \multicolumn{9}{|c|}{ Faecal haemoglobin $>10 \mu \mathrm{g} / \mathrm{g}$ faeces, secondary care } \\
\hline Sieg 1998 & 41 & 167 & 2 & 529 & 0.95 (0.84 to 0.99$)$ & $0.76(0.73$ to 0.79$)$ & $0.20(0.15$ to 0.26$)$ & $0.00(0.00$ to 0.01$)$ \\
\hline Sieg 1999 & 20 & 71 & 3 & 527 & 0.87 (0.66 to 0.97$)$ & $0.88(0.85$ to 0.91$)$ & $0.22(0.14$ to 0.32$)$ & $0.01(0.00$ to 0.02$)$ \\
\hline
\end{tabular}

Combination tests, positive $v$ negative result

Fecatwin/Feca ElA, no info on diet (combined guaiac and immunochemical), secondary care

$\begin{array}{llllll}\text { Pye } 1989 & 16 & 52 & 8 & 459 & 0.67 \text { ( } 0.45 \text { to } 0.84)\end{array}$ $0.88(0.85$ to 0.91$)$ 0.22 (0.14 to 0.32 ) $0.01(0.00$ to 0.02$)$

$\mathrm{TP}=$ true positives; $\mathrm{FP}=$ false positives; $\mathrm{FN}=$ false negatives; $\mathrm{TN}=$ true negatives. 
Table 12 | Results of preplanned subgroup analyses between studies

\begin{tabular}{|c|c|c|c|c|}
\hline \multirow[b]{2}{*}{ Analyses (No of studies) } & \multicolumn{2}{|c|}{$\begin{array}{l}\text { Sensitivity (range or pooled } \\
\left.\text { estimate }(95 \% \mathrm{Cl})^{\star}\right)\end{array}$} & \multicolumn{2}{|c|}{$\begin{array}{l}\text { Specificity (range or pooled estimate } \\
\left.\qquad(95 \% \mathrm{Cl})^{\star}\right)\end{array}$} \\
\hline & 1st subgroup & 2nd subgroup & 1st subgroup & 2nd subgroup \\
\hline \multicolumn{5}{|l|}{ Weight loss } \\
\hline Primary (6) v secondary care (6) & $0.13-0.44$ & $0.23(0.17-0.30)$ & $0.85-0.94$ & 0.90 (0.84 to 0.93$)$ \\
\hline Prevalence $\triangleleft 5 \%(6) v \geq 5 \%(7)$ & $0.21(0.15$ to 0.29$)$ & $0.13-0.37$ & $0.91(0.86$ to 0.94$)$ & $0.72-0.94$ \\
\hline QUADAS item 5 (no bias (5) v potential bias (6)) & 0.21 (0.13 to 0.31$)$ & $0.13-0.37$ & 0.89 (0.86 to 0.92$)$ & $0.72-0.95$ \\
\hline \multicolumn{5}{|l|}{ Abdominal pain } \\
\hline Primary (6) v secondary care (13) & $0.00-0.40$ & $0.00-0.73$ & 0.49-0.91 & $0.19-0.84$ \\
\hline Prevalence $5 \%$ (8) $v \geq 5 \%$ (12) & $0.00-0.50$ & $0.00-0.73$ & $0.29-0.84$ & $0.19-0.91$ \\
\hline QUADAS item 5 (no bias (10) $v$ potential bias (8)) & $0.00-0.44$ & $0.00-0.73$ & $0.49-0.77$ & $0.19-0.82$ \\
\hline QUADAS item 7 (no bias (7) $v$ potential bias (11)) & $0.00-0.49$ & $0.00-0.73$ & $0.29-0.82$ & 0.19-0.91 \\
\hline \multicolumn{5}{|l|}{ Blood in stools } \\
\hline Prevalence $\triangleleft 5 \%(6) v \geq 5 \%(7)$ & $0.25-0.86$ & $0.38-0.71$ & $0.31-0.88$ & $0.36-0.72$ \\
\hline QUADAS item 5 (no bias (5) v potential bias (6)) & $0.25-0.71$ & $0.51-0.85$ & $0.31-0.44$ & $0.36-0.72$ \\
\hline QUADAS item 7 (no bias (6) $v$ potential bias (6)) & $0.44(0.33$ to 0.55$)$ & $0.25-0.71$ & 0.72 (0.66 to 0.78$)$ & $0.37-0.88$ \\
\hline \multicolumn{5}{|l|}{ Change in bowel habit } \\
\hline Primary (6) $v$ secondary care (12) & $0.10-1.00$ & $0.06-0.86$ & $0.55-0.93$ & $0.28-0.94$ \\
\hline Prevalence $<5 \%$ (8) $v \geq 5 \%$ (10) & $0.06-1.00$ & $0.10-0.77$ & $0.28-0.94$ & $0.52-0.93$ \\
\hline QUADAS item 5 (no bias (10) $v$ potential bias (6)) & $0.06-1.00$ & $0.20-0.46$ & $0.52-0.94$ & $0.54-0.79$ \\
\hline QUADAS item 7 (no bias (7) $v$ potential bias (9)) & $0.06-0.64$ & $0.20-1.00$ & $0.55-0.94$ & $0.52-0.79$ \\
\hline \multicolumn{5}{|l|}{ Guiac based faecal occult blood test $\dagger$} \\
\hline Prevalence $<5 \%$ (6) $v \geq 5 \%$ (8) & $0.75(0.63$ to 0.84$)$ & $0.54-1.00$ & $0.82(0.75$ to 0.87$)$ & $0.82-0.93$ \\
\hline Diet yes (4) $v$ no (4) & $0.67(0.53$ to 0.79$)$ & $0.73-0.92$ & $0.85(0.76$ to 0.91$)$ & $0.73-0.93$ \\
\hline QUADAS item 5 (no bias (4) v potential bias (9)) & $0.82(0.71$ to 0.90$)$ & $0.54-1.00$ & $0.83(0.72$ to 0.91$)$ & $0.79-0.93$ \\
\hline QUADAS item 7 (no bias (5) v potential bias (9)) & 0.80 (0.69 to 0.88$)$ & $0.54-1.00$ & $0.82(0.75$ to 0.87$)$ & $0.73-0.89$ \\
\hline
\end{tabular}

value). Other symptoms, including presence of diarrhoea, constipation, change in bowel habit, or abdominal pain, showed poor diagnostic performance.

Studies showed a high degree of heterogeneity. This might be because studies used different definitions to classify self reported symptoms such as change in bowel habit. Furthermore, studies used different inclusion criteria, leading to an increased risk of selection bias in several studies. For example, in seven out of 10 primary care studies that reported on the diagnostic performance of signs and symptoms in symptomatic patients, rectal bleeding was used as inclusion

$\begin{aligned} & \text { Two week referral } \\ & \text { clinics }\end{aligned}$
Chohan 2005
Flashman 2004
Secondary care
Bafandeh 2008
Bjerregaard 2007
Panzuto 2003
Tan 2002
Tate 1998
Pepin 2002
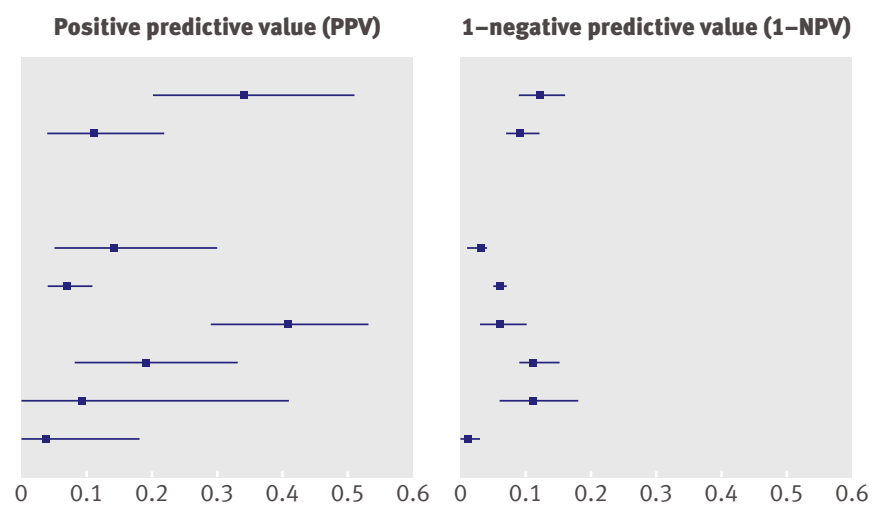

Fig $7 \mid$ Risk of colorectal cancer in patients with iron deficiency anaemia (positive predictive value) versus risk in patients without (1-negative predictive value) criterion, thereby selecting a higher risk group. It is unlikely that the results of these studies are directly applicable to all primary care patients consulting their general practitioner with lower abdominal signs and symptoms.

\section{Family history}

Family history showed a high specificity combined with a low sensitivity. Its diagnostic value in primary care is limited, however, because only a small percentage of all cases have a family history. In the UK and other countries patients with a familial link are often referred for genetic assessment instead of immediate investigation with colonoscopy, which often results in a screening advice. The NICE guidelines for colorectal cancer state that there is insufficient evidence for the value of family history in symptomatic patients. ${ }^{73}$ The few studies in our review that presented information on family history showed heterogeneous results for diagnostic performance. To firmly establish the diagnostic performance of family history in symptomatic patients we need a clear definition for a "positive family history," which describes the number, age, and degree of affected family members.

\section{Combinations of symptoms and two week referral guidelines}

Our results indicate that while the diagnostic performance of individual signs and symptoms is limited, 
Table 13 | Within study comparisons of sensitivity and specificity for various types of faecal occult blood test (FOBT)

\begin{tabular}{|c|c|c|c|c|}
\hline & \multicolumn{2}{|c|}{ Sensitivity } & \multicolumn{2}{|c|}{ Specificity } \\
\hline & No & Sensitivity & No & Specificity \\
\hline \multicolumn{5}{|c|}{ Guaiac based FOBT $v$ immunochemical based FOBT } \\
\hline \multicolumn{5}{|l|}{ Thomas $^{58}$} \\
\hline Guaiac based (Haemoccult, diet) & $29 / 50$ & 0.58 & $262 / 282$ & 0.93 \\
\hline Immunochemical based (Hemeselect) & $47 / 50$ & 0.94 & $220 / 282$ & 0.78 \\
\hline \multicolumn{5}{|l|}{ Jeanson ${ }^{36}$} \\
\hline Guaiac based (Haemoccult, no diet) & $8 / 11$ & 0.73 & $102 / 124$ & 0.82 \\
\hline Immunochemical based (Hemeselect) & $11 / 11$ & 1.00 & $100 / 124$ & 0.81 \\
\hline Immunochemical based (Hemoblot) & $11 / 11$ & 1.00 & $95 / 124$ & 0.77 \\
\hline \multicolumn{5}{|l|}{ Smith ${ }^{53}$} \\
\hline Guaiac based (Haemoccult, Sensa, diet) & $5 / 7$ & 0.71 & $135 / 154$ & 0.88 \\
\hline Immunochemical based (InSure) & $7 / 7$ & 1.00 & $124 / 154$ & 0.81 \\
\hline \multicolumn{5}{|l|}{ Regular $v$ self test } \\
\hline \multicolumn{5}{|l|}{$\mathrm{Pye}^{48}$} \\
\hline Regular (Haemoccult, no info diet) & $13 / 24$ & 0.54 & $328 / 359$ & 0.91 \\
\hline Self test (Coloscreen, no info diet) & $8 / 24$ & 0.33 & $331 / 353$ & 0.94 \\
\hline \multicolumn{5}{|l|}{ Tate $^{56}$} \\
\hline Regular (Haemoccult, no info diet) & $12 / 15$ & 0.80 & $230 / 260$ & 0.88 \\
\hline Self test (E-Z Detect, no info diet) & $8 / 22$ & 0.36 & $341 / 382$ & 0.89 \\
\hline \multicolumn{5}{|l|}{ Tate $^{57}$} \\
\hline Regular (Fecatwin, no info diet) & $14 / 15$ & 0.93 & $229 / 320$ & 0.72 \\
\hline Regular (Haemoccult, no info diet) & $16 / 20$ & 0.80 & $262 / 292$ & 0.89 \\
\hline Self test (E-Z Detect, no info diet) & $8 / 14$ & 0.50 & $271 / 305$ & 0.89 \\
\hline
\end{tabular}

combinations of symptoms improve the sensitivity at the cost of specificity as these symptoms are common in primary care. The two week referral guideline combines symptoms, resulting in a high sensitivity (range $0.80-0.94$, median 0.92$)$ and low specificity $(0.30-0.56$, $0.42)$.

Haemoccult, diet (Castiglione 1987, primary care) Fecatwin/Feca, no information on diet (Pye 1989) Fecatwin, no information on diet (Tate 1990) Haemoccult, diet (Goulston 1980) Haemoccult, diet (Thomas 1992) Haemoccult, diet (Niv 1995)

Haemoccult, no diet (Falkson 1993) Haemoccult, no diet (Jeanson 1994) Haemoccult, no diet (Kimming 1989) Haemoccult, no diet (Leicester 1983)

Haemoccult, no information on diet (Farrands 1985) Haemoccult, no information on diet (Pye 1990) Haemoccult, no information on diet (Tate 1989) Haemoccult, no information on diet (Tate 1990)

Haemoccult Sensa, diet (Smith 2006)

Self test Coloscreen, no information on diet (Pye 1990) Self test E-Z Detect, no information on diet (Tate 1989) Self test E-Z, no information on diet (Tate 1990)

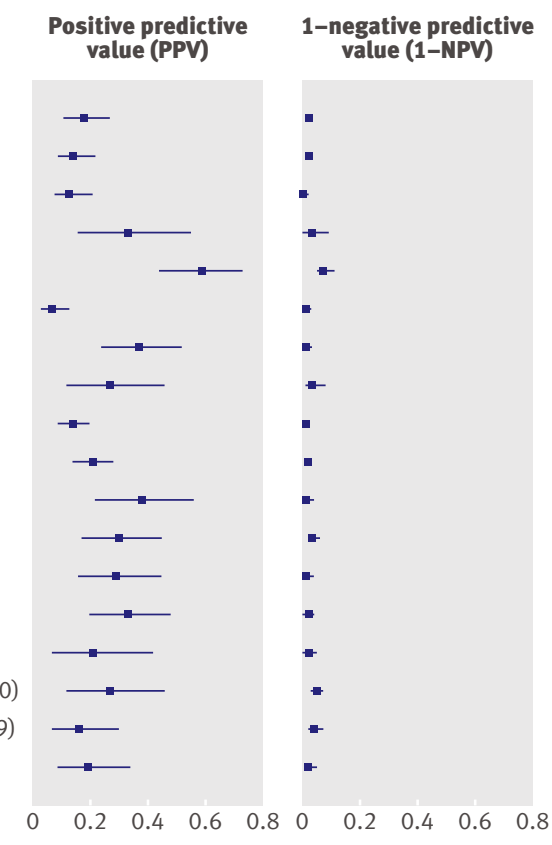

Fig 8 | Risk of colorectal cancer in patients with positive guaiac based faecal occult blood test result (positive predictive value) versus risk in patients with negative result (1-negative predictive value)
In their review of the two week referral guideline Hamilton and Sharp ${ }^{6}$ conclude that rectal bleeding and change in bowel habit have a high predictive value for colorectal cancer, which is in contrast with the conclusion of the review of Ford et al. ${ }^{74}$ In our review only a few studies reported a significantly higher risk for colorectal cancer among patients reporting one of these symptoms compared with those without the symptom, indicating that the two week referral guideline might provide only limited diagnostic information. Heterogeneity in diagnostic value of a referral guideline could be due to the inclusion of different "tests." Most favourable combinations of sensitivity and specificity were found for a prediction rule consisting of age, change in bowel habit, and blood in stools (sensitivity 1.0, specificity 0.9 ), but a study on the external validity of this prediction rule could not confirm these favourable results. ${ }^{72}$ Our review shows that $12 \%$ to $25 \%$ (median 14\%) of the patients referred by the two week referral guideline were eventually diagnosed with colorectal cancer. Refining the current referral system could help to improve specificity.

\section{Blood tests}

We found a low sensitivity for blood tests (haemoglobin, erythrocyte sedimentation rate, white cell count) in detecting colorectal cancer. The median probability of cancer in patients with anaemia (positive predictive value) was only slightly higher than in patients with negative test results, indicating limited diagnostic performance of this test in clinical practice when used as a single test. This is in accordance with the NICE guidelines. ${ }^{73}$ Despite this, they might provide a useful adjunct to the general medical investigation, with conditions such as iron deficiency anaemia warranting further investigation. ${ }^{6}$

\section{Faecal occult blood tests}

We found relatively good results for diagnostic performance of the faecal occult blood tests, especially for the immunochemical based test, which showed high sensitivity and reasonable specificity in most studies. The probability of colorectal cancer is clearly higher in patients with positive rather than negative findings on the test. These favourable findings for the immunochemical based test contrast with the NICE guideline ${ }^{73}$ which states that in patients with abdominal symptoms, the sensitivity, specificity, and positive predictive values of faecal occult blood tests are too low to make these tests helpful.

We did, however, find large heterogeneity in the results of studies on both guaiac based and immunochemical based tests. This might be because of different types of faecal occult blood tests being used in the primary studies. Furthermore, publications often lacked information on dietary restrictions, the definition of a positive test result (cut-off value, number of positive samples), and number of test failures. Not providing a dietary advice has been reported to affect the specificity of guaiac based tests, ${ }^{13}$ but our review could not confirm this. Overall, analyses both between and 
Table 14 |Within study comparison of sensitivities for various tumour stages and locations according to positive result on guaiac based or immunochemical based faecal occult blood test

Guaiac based test

No Sensitivity

Dukes's stage

Thomas $^{58}$

\begin{tabular}{ccccc}
\hline A & $4 / 8$ & 0.50 & $7 / 8$ & 0.88 \\
\hline B & $11 / 21$ & 0.52 & $21 / 21$ & 1.00 \\
\hline C & $9 / 13$ & 0.69 & $12 / 13$ & 0.92 \\
\hline D & $7 / 8$ & 0.88 & $7 / 8$ & 0.88 \\
\hline Smith $^{53}$ & & & & \\
\hline A & $1 / 3$ & 0.33 & $3 / 3$ & 1.00 \\
\hline B & $1 / 1$ & 1.00 & $1 / 1$ & 1.00 \\
\hline C & $3 / 3$ & 1.00 & $3 / 3$ & 1.00 \\
\hline D & - & - & - & - \\
\hline
\end{tabular}

Location

\begin{tabular}{lcccc}
\hline Thomas $^{58}$ & & & & \\
\hline Rectum & $13 / 25$ & 0.52 & $24 / 25$ & 0.96 \\
\hline Other left sided cancer & $11 / 15$ & 0.73 & $14 / 15$ & 0.93 \\
\hline Right sided cancer & $5 / 10$ & 0.50 & $9 / 10$ & 0.90
\end{tabular}

within studies showed better diagnostic performance of immunochemical based than guaiac based tests and that guaiac based self tests seemed to perform less well than the regular guaiac based tests.

Subgroup analyses within studies based on small numbers seemed to indicate that immunochemical based tests were more sensitive in detecting early stages of cancer than guaiac based tests. ${ }^{538}$ As early stages have far better prognoses this is an important finding. One of these studies also showed that immunochemical based tests were better than guaiac based tests at detecting colorectal cancer at all sites. ${ }^{58}$ These results need confirmation in future, larger studies.

\section{Strengths and weaknesses of our review}

We extracted or reconstructed diagnostic data collected from symptomatic patients in primary and
HemeSelect (Jeanson 1994) Hemeselect (Thomas 1992) Hemoblot (Jeanson 1994) iFOBT strip (Shastri 2008) Immunohemostick (Miyoshi 2000) Insure (Smith 2006) Fecal HbAb (Sieg 1998) Fecal HbHp (Seig 1999) Fecal Hb (Levi 2007)

Fecal Hb (Sieg 1998) Fecal Hb (Sieg 1999)

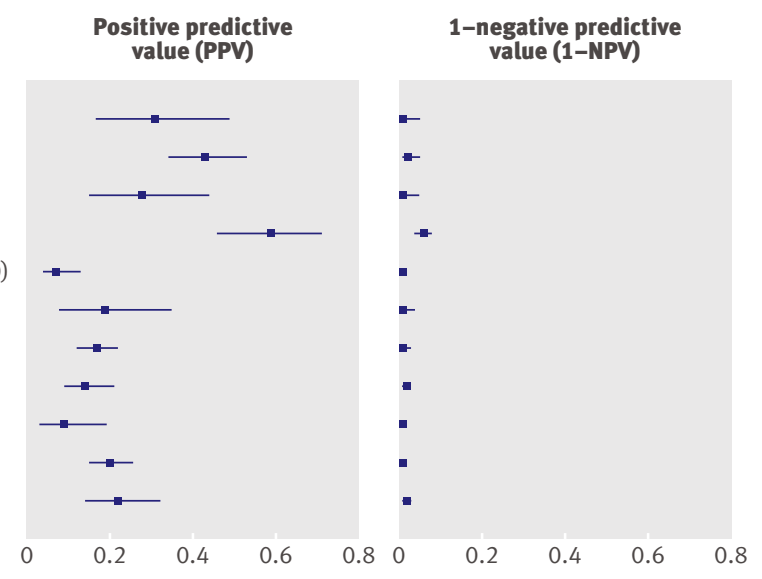

Fig 9 | Risk of colorectal cancer in patients with positive immunochemical based faecal occult blood test result (positive predictive value) versus risk in patients with negative results (1-negative predictive value). All studies were conducted in secondary care. $\mathrm{HbAb}=$ haemoglobin-albumin complex, $\mathrm{HbHp}=$ haemoglobin-haptoglobin complex interface settings and excluded information from healthy (screening studies) or highly selected diseased controls, thereby preventing limited challenge bias. ${ }^{75}$

Furthermore, we studied a whole range of diagnostic tools that are available to general practitioners instead of focusing on only one or two tests. We adhered to the most recent guidelines for conducting a diagnostic review as described in the Cochrane Diagnostic Reviewers' Handbook. ${ }^{21}$ We used an extensive search strategy, but by using a methodological filter we might have missed several relevant publications. By reference checking we tried to track down those publications that our search strategy might have failed to identify. Use of a language restriction during the selection phase led to the exclusion of only $0.7 \%$ of all citations.

There were quite a few discrepancies in the phase of abstract selection. The first reviewer used a highly sensitive approach and selected all abstracts that could in any way be relevant to the review, with the aim of not missing any relevant papers. The second reviewer subsequently considered all these pre-selected abstracts and excluded those that clearly did not meet the eligibility criteria. Anticipating poor agreement on some items of the QUADAS list, ${ }^{7677}$ two reviewers independently assessed all papers for methodological quality and reached consensus by discussing disagreements on individual scores.

The studies of the various tests showed a high degree of clinical heterogeneity, which limited the possibilities for statistical pooling and strong conclusions on diagnostic performance. Reasons for heterogeneity include different definitions of signs and symptoms, variation in executions of tests (such as faecal occult blood tests), and selection of populations based on particular symptoms or complaints.

In subgroup analyses we took into account the generally poor reporting of diagnostic accuracy ${ }^{78}$ by excluding studies providing insufficient information on the characteristic under study. Finally, we extensively explored many potential sources of heterogeneity, including the adequacy of the reference standard. Because of the small number of studies in the subgroups, we could not use multivariable meta-regression analysis, making it difficult to disentangle the contribution of each source of heterogeneity.

\section{Recommendations}

Diagnostic tests as first line investigation in primary care need to be valid, easy to perform, well tolerated by patients, and sensitive, especially in case of serious disease. Our systematic review shows that immunochemical based faecal occult blood tests might prove to be such tests. Evidence is lacking, however, for the diagnostic performance of these tests in primary care populations. We therefore urgently need high quality diagnostic cohort studies enrolling consecutive patients presenting with non-acute abdominal symptoms in primary care. Symptom combinations or two week referral guidelines potentially have diagnostic value, but the performance of the guideline could be 


\section{WHAT IS ALREADY KNOWN ON THIS TOPIC}

To improve the prognosis of colorectal cancer the diagnosis should be made at an early stage

An important task for the primary care physician is to identify the patients with an increased risk for colorectal cancer among all those consulting for abdominal symptoms

\section{WHAT THIS STUDY ADDS}

The most promising primary care tests in terms of diagnostic performance are combinations of symptoms and faecal occult blood tests, especially immunochemical based tests

improved by standardisation, clear definitions, and the addition of important characteristics of those diagnosed with colorectal cancer but not fulfilling the current guideline.

In future research, cancer location and stage of disease should be an important factor in the analysis, especially as tests that are able to diagnose early stages of colorectal cancer are important tools to reduce the burden of cancer.

Contributors: DvdW secured funding. PJ and DvdW selected studies for inclusion. PJ, HdV, DvdW, and DB extracted data and assessed quality. P carried out the statistical analyses and wrote the original draft. The other authors (DvdW, DB, CDM, SvW, CJM, HdV) revised the draft critically for important intellectual content and approved the final version of the paper. PI and DvdW are guarantors.

Funding: The study was supported by a grant from the Netherlands Organisation for Health Research and Development (ZonMw). The Hague, Netherlands (No 945-06-001). ZonMw had no involvement in study design; in the collection, analysis and interpretation of data; in the writing of the report; and in the decision to submit the paper for publication.

Competing interests: None declared.

Ethical approval: Not required.

Data sharing: The full search strategies can be obtained from the corresponding author (hcw.devet@vumc.nl) on request.

1 Ferlay I, Autier P, Boniol M, Heanue M, Colombet M, Boyle P. Estimates of the cancer incidence and mortality in Europe in 2006. Ann Oncol 2007;18:581-92.

2 Davila RE, Rajan E, Baron TH, Adler DG, Egan JV, Faigel DO, et al. ASGE guideline: colorectal cancer screening and surveillance. Gastrointest Endosc 2006;63:546-57.

3 O'Connell JB, Maggard MA, Ko CY. Colon cancer survival rates with the new American Joint Committee on Cancer sixth edition staging. I Natl Cancer Inst 2004;96:140-5.

4 Hamilton W, Round A, Sharp D, Peters TJ. Clinical features of colorectal cancer before diagnosis: a population-based case-control study. Br J Cancer 2005;93:399-405.

5 Janssen HA, Borghouts JA, Muris JW, Metsemakers JF, Koes BW, Knottnerus JA. Health status and management of chronic nonspecific abdominal complaints in general practice. Br J Gen Pract 2000;50:375-9.

6 Hamilton W, Sharp D. Diagnosis of colorectal cancer in primary care: the evidence base for guidelines. Fam Pract 2004;21:99-106.

7 Department of Health. Referral guidelines for suspected cancer. Department of Health, 2000.

8 Selvachandran SN, Hodder RJ, Ballal MS, Jones P, Cade D. Prediction of colorectal cancer by a patient consultation questionnaire and scoring system: a prospective study. Lancet 2002;360:278-83.

9 Rai S, Kelly MJ. Prioritization of colorectal referrals: a review of the 2week wait referral system. Colorectal Dis 2007;9:195-202.

10 Thorne K, Hutchings HA, Elwyn G. The effects of the two-week rule on NHS colorectal cancer diagnostic services: a systematic literature review. BMC Health Serv Res 2006;6:43.

11 Falkson CB, Bates T. Faecal occult blood screening for patients with gastrointestinal symptoms. Br/ Surg 1993;80:1326.

12 Farrands PA, O'Regan D, Taylor I. An assessment of occult blood testing to determine which patients with large bowel symptoms require urgent investigation. Br J Surg 1985;72:835-7.

13 Greenwald B. From guaiac to immune fecal occult blood tests: the emergence of technology in colorectal cancer screening. Gastroenterol Nurs 2005;28:90-6.
14 Parekh M, Fendrick AM, Ladabaum U. As tests evolve and costs of cancer care rise: reappraising stool-based screening for colorectal neoplasia. Aliment Pharmacol Ther 2008;27:697-712.

15 Cole SR, Smith A, Wilson C, Turnbull D, Esterman A, Young GP. An advance notification letter increases participation in colorectal cancer screening. J Med Screen 2007;14:73-5.

16 Bachmann LM, Coray R, Estermann P, Ter Riet G. Identifying diagnostic studies in Medline: reducing the number needed to read. Am Med Inform Assoc 2002;9:653-8.

17 Deville WL, Buntinx F, Bouter LM, Montori VM, de Vet HC, van der Windt DA, et al. Conducting systematic reviews of diagnostic studies: didactic guidelines. BMC Med Res Methodol 2002;2:9.

18 Haynes RB, Wilczynski NL. Optimal search strategies for retrieving scientifically strong studies of diagnosis from Medline: analytical survey. BMJ 2004;328:1040.

19 Muris JW, Starmans R, Fijten GH, Crebolder HF, Schouten HJ, Knottnerus JA. Non-acute abdominal complaints in general practice: diagnostic value of signs and symptoms. Br / Gen Pract 1995;45:313-6

20 Whiting P, Rutjes AW, Reitsma JB, Bossuyt PM, Kleijnen J. The development of QUADAS: a tool for the quality assessment of studies of diagnostic accuracy included in systematic reviews. BMC Med Res Methodol 2003;3:25.

21 Cochrane Collaboration. Cochrane diagnostic reviewers' handbook. John Wiley, 2005.

22 Lijmer JG, Mol BW, Heisterkamp S, Bonsel GJ, Prins MH, van der Meulen JH, et al. Empirical evidence of design-related bias in studies of diagnostic tests. JAMA 1999;282:1061-6.

23 Rutjes AWS, Reitsma JB, Di Nisio M, Smidt N, van Rijn JC, Bossuyt PMM. Evidence of bias and variation in diagnostic accuracy studies. CMAI 2006;174:469-76.

24 Zamora J, Muriel A, Abrair V. Statistical methods. MetaDiSc version 1.4, 2004.

25 Reitsma JB, Glas AS, Rutjes AW, Scholten RJ, Bossuyt PM, Zwinderman AH. Bivariate analysis of sensitivity and specificity produces informative summary measures in diagnostic reviews. $J$ Clin Epidemiol 2005;58:982-90.

26 Gatsonis C, Paliwal P. Meta-analysis of diagnostic and screening test accuracy evaluations: methodologic primer. AJR Am J Roentgenol 2006;187:271-81.

27 Bafandeh Y, Khoshbaten M, Eftekhar Sadat AT, Farhang S. Clinical predictors of colorectal polyps and carcinoma in a low prevalence region: results of a colonoscopy based study. World J Gastroenterol 2008;14:1534-8.

28 Barwick TW, Scott SB, Ambrose NS. The two week referral for colorectal cancer: a retrospective analysis. Colorectal Dis 2004;6:85-91.

29 Bjerregaard NC, Tottrup A, Sorensen HT, Laurberg S. Diagnostic value of self-reported symptoms in Danish outpatients referred with symptoms consistent with colorectal cancer. Colorectal Dis 2007;9:443-51.

30 Bjerregaard NC, Tottrup A, Sorensen HT, Laurberg S. Evaluation of the Danish national strategy for selective use of colonoscopy in symptomatic outpatients without known risk factors for colorectal cancer. Scand J Gastroenterol 2007;42:228-36.

31 Castiglione G, Pacini F, Palli D. Haemoccult test and a selfadministered questionnaire in the early diagnosis of colorectal cancer. Ital J Gastroenterol 1987;19:83-6.

32 Charalambopoulos A, Syrigos KN, Ho JL, Murday VA, Leicester RJ. Colonoscopy in symptomatic patients with positive family history of colorectal cancer. Anticancer Res 2000;20:1991-4.

33 Ellis BG, Thompson MR. Factors identifying higher risk rectal bleeding in general practice. Br/Gen Pract 2005;55:949-55.

34 Fijten GH, Starmans R, Muris JW, Schouten HJ, Blijham GH, Knottnerus JA. Predictive value of signs and symptoms for colorectal cancer in patients with rectal bleeding in general practice. Fam Pract 1995;12:279-86.

35 Goulston K, Davidson P. Faecal occult blood testing in patients with colonic symptoms. Med / Aust 1980;2:667-8.

36 Jeanson A, Jamart J, Maisin JM, Vanheuverzwyn R, Gohy P, Debongnie JC, et al. Assessment of the new immunological test Hemoblot for detecting occult blood in faeces. Eur J Cancer Prev 1994;3:407-12

37 Kimmig JM, Strauch M, Hallen M. Negative Haemoccult test in malignant and premalignant lesions of the colon. Validation of the Haemoccult test with total colonoscopy. Endoscopy 1989;21:136-40.

38 Leicester RJ, Lightfoot A, Millar J, Colin-Jones DG, Hunt RH. Accuracy and value of the Hemoccult test in symptomatic patients. BMJ 1983;286:673-4.

39 Levi Z, Rozen P, Hazazi R, Vilkin A, Waked A, Maoz E, et al. A quantitative immunochemical fecal occult blood test for colorectal neoplasia. Ann Intern Med 2007;146:244-55. 
40 Mant A, Bokey EL, Chapuis PH, Killingback M, Hughes W, Koorey SG, et al. Rectal bleeding. Do other symptoms aid in diagnosis? Dis Colon Rectum 1989;32:191-6.

41 Marderstein EL, Church JM. Classic "outlet" rectal bleeding does not require full colonoscopy to exclude significant pathology. Dis Colon Rectum 2008;51:202-6.

42 Miyoshi H, Oka M, Sugi K, Saitoh O, Katsu K, Uchida K. Accuracy of detection of colorectal neoplasia using an immunochemical occult blood test in symptomatic referred patients: comparison of retrospective and prospective studies. Intern Med 2000;39:701-6.

43 Niv Y, Sperber AD. Sensitivity, specificity, and predictive value of fecal occult blood testing (Hemoccult II) for colorectal neoplasia in symptomatic patients: a prospective study with total colonoscopy. Am J Gastroenterol 1995;90:1974-7.

44 Norrelund N, Norrelund H. Colorectal cancer and polyps in patients aged 40 years and over who consult a GP with rectal bleeding. Fam Pract 1996;13:160-5.

45 Panzuto F, Chiriatti A, Bevilacqua S, Giovannetti P, Russo G, Impinna S, et al. Symptom-based approach to colorectal cancer: survey of primary care physicians in Italy. Dig Liver Dis 2003;35:869-75.

46 Pepin C, Ladabaum U. The yield of lower endoscopy in patients with constipation: survey of a university hospital, a public county hospital, and a Veterans Administration medical center. Gastrointest Endosc 2002;56:325-32.

47 Pye G, Marks CG, Martin S, Marks V, Jackson J, Hardcastle JD. An evaluation of Fecatwin/Feca EIA; a faecal occult blood test for detecting colonic neoplasia. Eur / Surg Oncol 1989;15:446-8.

48 Pye G, Jackson J, Thomas WM, Hardcastle JD. Comparison of Coloscreen Self-Test and Haemoccult faecal occult blood tests in the detection of colorectal cancer in symptomatic patients. Br J Surg 1990;77:630-1.

49 Robertson R, Campbell C, Weller DP, Elton R, Mant D, Primrose J, et al. Predicting colorectal cancer risk in patients with rectal bleeding. $\mathrm{Br}$ J Gen Pract 2006;56:763-7.

50 Shastri YM, Loitsch S, Hoepffner N, Povse N, Hanisch E, Rosch W, et al. Comparison of an established simple office-based immunological FOBT with fecal tumor pyruvate kinase type M2 (M2 $\mathrm{PK})$ for colorectal cancer screening: prospective multicenter study. Am J Gastroenterol 2008;103:1496-504.

51 Sieg A, Scheida M, John MR, Hertel A, Schroter M, Luthgens K, et al. Validity of new immunological human fecal hemoglobin and albumin tests in detecting colorectal neoplasms-an endoscopy-controlled study. Z Gastroenterol 1998;36:485-90.

52 Sieg A, Thoms C, Luthgens K, John MR, Schmidt-Gayk H. Detection of colorectal neoplasms by the highly sensitive hemoglobinhaptoglobin complex in feces. Int / Colorectal Dis 1999;14:267-71.

53 Smith A, Young GP, Cole SR, Bampton P. Comparison of a brushsampling fecal immunochemical test for hemoglobin with a sensitive guaiac-based fecal occult blood test in detection of colorectal neoplasia. Cancer 2006;107:2152-9.

54 Steine S, Stordahl A, Laerum F, Laerum E. Referrals for doublecontrast barium examination. Factors influencing the probability of finding polyps or cancer. Scand J Gastroenterol 1994;29:260-4.

55 Tan YM, Rosmawati M, Ranjeev P, Goh KL. Predictive factors by multivariate analysis for colorectal cancer in Malaysian patients undergoing colonoscopy. J Gastroenterol Hepatol 2002;17:281-4

56 Tate JJ, Northway J, Royle GT, Taylor I. Evaluation of a 'DIY' test for the detection of colorectal cancer. J R Soc Med 1989;82:388-90.

57 Tate JJ, Northway J, Royle GT, Taylor I. Faecal occult blood testing in symptomatic patients: comparison of three tests. Br J Surg 1990;77:523-6.

58 Thomas WM, Hardcastle JD, Jackson J, Pye G. Chemical and immunological testing for faecal occult blood: a comparison of two tests in symptomatic patients. Br J Cancer 1992;65:618-20.
59 Thompson MR, Perera R, Senapati A, Dodds S. Predictive value of common symptom combinations in diagnosing colorectal cancer. $\mathrm{Br}$ I Surg 2007;94:1260-5.

60 Thompson MR, Flashman KG, Wooldrage K, Rogers PA, Senapati A, O'Leary DP, et al. Flexible sigmoidoscopy and whole colonic imaging in the diagnosis of cancer in patients with colorectal symptoms. $\mathrm{Br}$ J Surg 2008;95:1140-6.

61 Wauters H, Van Casteren V, Buntinx F. Rectal bleeding and colorectal cancer in general practice: diagnostic study. BMJ 2000;321:998-9.

62 Zarchy TM, Ershoff D. Which clinical variables predict an abnormal double-contrast barium enema result? Ann Intern Med 1991;114:137-41.

63 Bellentani S, Baldoni P, Petrella S, Tata C, Armocida C, Marchegiano P, et al. A simple score for the identification of patient at high risk of organic diseases of the colon in the family doctor consulting room. The Local IBS Study Group. Fam Pract 1990;7:307-12.

64 Brewster NT, Grieve DC, Saunders JH. Double-contrast barium enema and flexible sigmoidoscopy for routine colonic investigation. $\mathrm{Br}$ J Surg 1994;81:445-7.

65 Chohan DP, Goodwin K, Wilkinson S, Miller R, Hall NR. How has the 'two-week wait' rule affected the presentation of colorectal cancer? Colorectal Dis 2005;7:450-3.

66 Debnath D, Dielehner N, Gunning KA. Guidelines, compliance, and effectiveness: a 12 months' audit in an acute district general healthcare trust on the two week rule for suspected colorectal cancer. Postgrad Med J 2002;78:748-51.

67 Eccersley AJ, Wilson EM, Makris A, Novell JR. Referral guidelines for colorectal cancer-do they work? Ann R Coll Surg Engl 2003;85:107-10.

68 Flashman K, O'Leary DP, Senapati A, Thompson MR. The Department of Health's "two week standard" for bowel cancer: is it working? Gut 2004;53:387-91.

69 Mahon CC, Vaizey C), Taylor I, Boulos PB. Preliminary evaluation of United Kingdom national referral guidelines for lower gastrointestinal tract cancer. Colorectal Dis 2002;4:111-4.

70 Metcalf JV, Smith J, Jones R, Record CO. Incidence and causes of rectal bleeding in general practice as detected by colonoscopy. $\mathrm{Br}$ Gen Pract 1996;46:161-4.

71 Tate JJ, Royle GT. Open access colonoscopy for suspected colonic neoplasia. Gut 1988;29:1322-5.

72 Hodder RJ, Ballal M, Selvachandran SN, Cade D. Pitfalls in the construction of cancer guidelines demonstrated by the analyses of colorectal referrals. Ann R Coll Surg Engl 2005;87:419-26.

73 National Institute for Health and Clinical Excellence. Referral for suspected cancer-NICE guideline. NICE, 2005.

74 Ford AC, Veldhuyzen van Zanten SJ, Rodgers CC, Talley NJ, Vakil NB, Moayyedi P. Diagnostic utility of alarm features for colorectal cancer: systematic review and meta-analysis. Gut 2008;57:1545-53.

75 Whiting P, Rutjes AW, Reitsma JB, Glas AS, Bossuyt PM, Kleijnen J. Sources of variation and bias in studies of diagnostic accuracy: a systematic review. Ann Intern Med 2004;140:189-202.

76 Hollingworth W, Medina LS, Lenkinski RE, Shibata DK, Bernal B, Zurakowski D, et al. Interrater reliability in assessing quality of diagnostic accuracy studies using the QUADAS tool. A preliminary assessment. Acad Radiol 2006;13:803-10.

77 Stengel D, Bauwens K, Rademacher G, Mutze S, Ekkernkamp A. Association between compliance with methodological standards of diagnostic research and reported test accuracy: meta-analysis of focused assessment of US for trauma. Radiology 2005;236:102-11.

78 Smidt N, Rutjes AW, van der Windt DA, Ostelo RW, Reitsma JB, Bossuyt PM, et al. Quality of reporting of diagnostic accuracy studies. Radiology 2005;235:347-53.

Accepted: 1 February 2010 